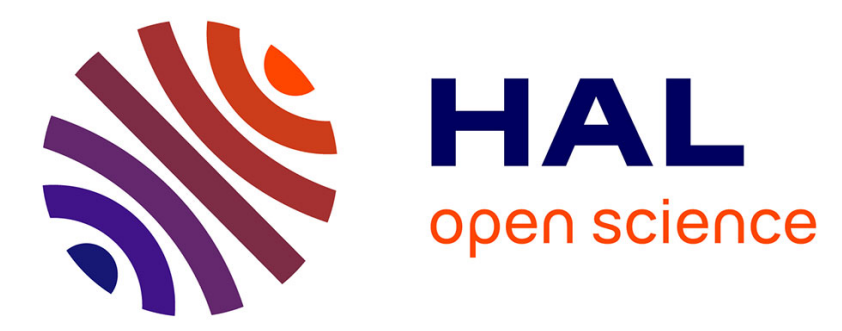

\title{
Graphene Synthesis by Microwave Plasma Chemical Vapor Deposition: Analysis of the Emission Spectra and Modeling
}

\author{
K Pashova, I. Hinkov, X Aubert, S Prasanna, F Bénédic, S Farhat
}

\section{- To cite this version:}

K Pashova, I. Hinkov, X Aubert, S Prasanna, F Bénédic, et al.. Graphene Synthesis by Microwave Plasma Chemical Vapor Deposition: Analysis of the Emission Spectra and Modeling. Plasma Sources Science and Technology, 2019, 28 (4), pp.045001. 10.1088/1361-6595/ab0b33 . hal-02394836

\section{HAL Id: hal-02394836 \\ https://hal.science/hal-02394836}

Submitted on 5 Dec 2019

HAL is a multi-disciplinary open access archive for the deposit and dissemination of scientific research documents, whether they are published or not. The documents may come from teaching and research institutions in France or abroad, or from public or private research centers.
L'archive ouverte pluridisciplinaire HAL, est destinée au dépôt et à la diffusion de documents scientifiques de niveau recherche, publiés ou non, émanant des établissements d'enseignement et de recherche français ou étrangers, des laboratoires publics ou privés. 


\title{
Graphene Synthesis by Microwave Plasma Chemical Vapor Deposition: Analysis of the Emission Spectra and Modeling
}

\author{
K. Pashova, ${ }^{1,2}$ I. Hinkov, ${ }^{2}$ X. Aubert ${ }^{1}$, S. Prasanna ${ }^{1}$, F. Bénédic ${ }^{1}$, and S. \\ Farhat $^{1, a)}$ \\ ${ }^{1}$ Laboratoire des Sciences des Procédés et des Matériaux, CNRS, LSPM - UPR 3407, Université Paris 13, PRES Sorbonne- \\ Paris-Cité, Villetaneuse, 93430, France \\ ${ }^{2}$ Département de Génie Chimique Université de Technologie Chimique et de Métallurgique, 8 Boulevard St. \\ Kliment Ohridski, 1756 Sofia, Bulgaria
}

\begin{abstract}
In this article, we report on some of the fundamental chemical and physical processes responsible for the deposition of graphene by microwave plasma-enhanced chemical vapor deposition (PECVD). The graphene is grown by plasma decomposition of a methane and hydrogen mixture $\left(\mathrm{CH}_{4} / \mathrm{H}_{2}\right)$ at moderate pressures over polycrystalline metal catalysts. Different conditions obtained by varying the plasma power (300-400 W), total pressure $(10-25 \mathrm{mbar})$, substrate temperature $\left(700-1000^{\circ} \mathrm{C}\right)$, methane flow rate $(1-10 \mathrm{sccm})$ and catalyst nature $(\mathrm{Co}-\mathrm{Cu})$ were experimentally analyzed using the in situ optical emission spectroscopy (OES) technique to assess the species rotational temperature of the plasma and the $\mathrm{H}$-atom relative concentration. Then, two modeling approaches were developed to analyze the plasma environment during graphene growth. As a first approximation, the plasma is described by spatially averaged bulk properties, and the species compositions are determined using kinetic rates in the transient zero-dimensional (0D) configuration. The advantage of this approach lies in its small computational demands, which enable rapid evaluation of the effects of reactor conditions and permit the identification of dominant reactions and key species during graphene growth. This approach is useful for identifying the relevant set of species and reactions to consider in a higher-dimensional model. The reduced chemical scheme was then used within the self-consistent two-dimensional model (2D) to determine auto-coherently the electromagnetic field, gas and electron temperatures, heavy species, and electron and ion density distributions in the reactor. The $0 \mathrm{D}$ and $2 \mathrm{D}$ models are validated by comparison with experimental data obtained from atomic and molecular emission spectra.
\end{abstract}

Keywords: graphene, plasma, CVD, optical emission spectroscopy, modeling

\section{INTRODUCTION}

Since the discovery of graphene, its unconventional two-dimensional (2D) electron gas properties and outstanding electrical, mechanical, and chemical properties have attracted considerable interest in condensedmatter physics and materials science [1]. This interest has made possible a large variety of commercial applications, including flexible transparent electrodes for displays and photovoltaics [2-6], fuel cells [7] and membranes for water purification [8,9] and desalination [10]. For such applications, the integration of graphene necessitates cost-effective large-area production by scalable processes. Due to its practicality and scalability, 
chemical vapor deposition (CVD) has become the most common method for graphene synthesis [11-13]. Indeed, CVD was already used to grow other carbon materials, such as diamond and carbon nanotubes, the growth of which is controlled by the surface energy. The key strategy is to break the symmetry by seeding with nanocrystalline diamond for three-dimensional (3D) diamond synthesis or to use a thin nanometric or micrometric metal catalyst for one-dimensional (1D) carbon nanotubes or 2D graphene growth, respectively. In this direction, CVD was continuously used in a roll-to-roll (R2R) process to manufacture up to $100 \mathrm{~m}$ lengths of graphene over $\mathrm{Cu}$ [14-19]. One of the advantages of the CVD process is the relatively uniform gas diffusion and heat transfer to the substrate during thermal or plasma decomposition of a carbon gas feedstock diluted with hydrogen over a polycrystalline or monocrystalline transition-metal catalyst. Various metals, such as Co [20,21], $\mathrm{Cu}[11,13,14,22-24], \mathrm{Ni}$ [2,12,25-29], Pd [30], Pt [31-33], Ru [34-37], Ir [36-40], Rh [41], Fe [45] and Au [43] and their alloys [44-47] have been proven to ensure a low-energy pathway by forming intermediate compounds during graphene growth. Despite this advantage, residual metal atoms can contaminate graphene during its transfer to the target wafer. To overcome this problem, CVD of graphene directly onto semiconducting $\mathrm{Si}$ was proposed [48]. However, the formation of carbide during the growth process makes manufacturing graphene on Si wafers extremely challenging [48,49]; the deposition of epitaxial germanium Ge layers onto $\mathrm{Si}$ wafers was therefore proposed for metal-free graphene CVD [49-51]. Nevertheless, planar polycrystalline transition metals such as $\mathrm{Co}, \mathrm{Ni}$, and $\mathrm{Cu}$ remain the most widely used catalysts due to their low cost and high availability.

The graphene growth process on $\mathrm{Co}, \mathrm{Ni}$, and $\mathrm{Cu}$ can be divided into four steps: (i) thermal annealing to reduce the native metal oxide film covering the catalyst surface and to enlarge the metal grains; (ii) carbon feedstock decomposition on the catalyst surface; (iii) nucleation, which is the result of competition between the rates of nucleus growth by adatom capture, the surface diffusion of carbon species and the desorption of carbon adatoms; and (iv) growth by attachment of active $\mathrm{C}$ species onto the graphene edge. However, based on experimental observation, two asymptotic regimes affect steps (iii) and (iv): the mass-transport regime, primarily related to diffusion through the boundary layer near the substrate, and the surface reaction regime, involving the crystallization of a supersaturated fraction of carbon-adatom species. The difference in the carbon solubility of metals ( 0.9 weight $\%$ of carbon at $1320^{\circ} \mathrm{C}$ for $\mathrm{Co}$ [52] and 0.008 weight $\%$ at $1084^{\circ} \mathrm{C}$ for $\mathrm{Cu}$ [53]) leads to two opposite phenomenological growth mechanisms, as studied by carbon isotope labeling [54]. The mechanism for high-carbon-solubility metals such as $\mathrm{Co}, \mathrm{Ni}, \mathrm{Pd}$, and $\mathrm{Ru}$ involves bulk diffusion followed by surface segregation-precipitation, whereas the mechanism involves surface diffusive growth when the solubility of carbon in the metals is low, such as for $\mathrm{Au}$ and $\mathrm{Cu}$. 
The size and the number of graphene layers can be controlled by the type of catalytic substrate and its crystal orientation as well as by the growth parameters. Various carbon feedstock sources have been successfully used to grow graphene, including solids such as spin-coated polymethylmethacrylate (PMMA) [23] fluorene, sucrose, food, insects, and waste [23,55-57]; liquid hydrocarbons such as benzene [58]; or more conventional gaseous hydrocarbons such as methane [11,59], ethane, propane [59] and ethylene [24]. Regardless of the carbon feedstock, molecular hydrogen is often added during catalyst annealing to reduce the native metal oxide film covering the catalyst surface as well as for graphene nucleation and growth. The hydrogen is assumed to affect the adsorption and the relative concentration of active carbon species on the catalyst surface and to contribute to graphene etching [60]. As the shape of graphene is the result of competition between graphene growth and etching, the shape can be tuned to rounded, hexagonal or branched via the partial pressure of hydrogen [61].

The energy required for the annealing and subsequent carbon feedstock decomposition can be obtained by thermal activation (T-CVD) [11-19]. However, in most T-CVD processes, the catalyst is heated by the entire reaction chamber volume through a hot-wall reactor, which is obviously less energy efficient and incompatible with scaling up the process. An alternative approach is to inductively heat the metal catalyst via magnetic fields [62-64]. This approach enables a high heating rate [62]; however, the chemical activation of the gas phase is limited to the substrate vicinity, i.e., at temperatures near the melting point of copper $\left(\sim 1050^{\circ} \mathrm{C}\right)$.

A radically opposite activation technique is to use plasma activation within plasma-enhanced chemical vapor deposition (PECVD) [65-77]. The ability of the plasma to support multiple reactive species concurrently is a key advantage. In addition to efficient removal of the native copper oxide and the smoothness of the copper substrate prepared by hydrogen plasma, PECVD can provide a rich chemical environment, including radicals, molecules and ions from hydrogen-hydrocarbon feedstock decomposition [75]. Compared with T-CVD, PECVD offers the advantage of lower operating substrate temperatures and higher gas decomposition rates. Thus, the surface reaction rate is reduced, but the nucleation and film quality are better controlled. Consequently, the surface topography of graphene grown via PECVD on $\mathrm{Cu}$ revealed sub-nanometer flatness [75]. PECVD reactors are generally cold-wall, and plasmas are generated by applying an external electric field to the process gases. Under steady-state conditions, mass transport can be described as a combination of several physical and chemical effects, including precursor diffusion through the gas boundary layer in the immediate vicinity of the substrate and chemical reactions in the gas phase and at the surface. Processes that occur on or near the surface are substantially affected by the substrate temperature. Indeed, this parameter affects the graphene nucleation 
density and growth rate, thereby controlling the final size of the graphene islands. In the specific case of graphene synthesized on metals, these fundamental processes are presumably influenced by several factors, including process parameters (gas and substrate temperature, pressure, carbon flow rate, growth time and dilution of carbon source in hydrogen content, cooling rate) and catalyst parameters (carbon solubility in the metal, crystal structure, lattice parameter, grain boundaries). The relative importance of these parameters changes as the reactor design and operating conditions vary. In addition, depending on the horizontal or vertical reactor position, gas-phase temperature gradients can produce density variations, leading to buoyancy-driven secondary flows superimposed on the main flow of the active carbon species. These secondary flows adversely affect gas-phase reactions and the spatial distributions of species, making analysis of the overall process difficult. To optimize the process, the authors of most published papers used trial-and-error approaches that more or less succeed to propose different recipes for producing high-quality, monolayer graphene in specific reactor geometry. Sensitivity analysis showed the effect of the individual parameters.

In our previous work [76], we used the Taguchi design method coupled with analysis of variance (ANOVA) to determine to the weightage of four parameters (i.e., substrate temperature, methane concentration, growth time and microwave power) during microwave (PECVD) graphene growth on cobalt substrates. To clarify the role of each growth parameter, a systematic study using thermochemical modeling is necessary. The global kinetics of hydrocarbons and the thermodynamics of carbon solubility have sometimes been proposed to explain graphene growth but are insufficient for capturing all the details of the process and efforts to control graphene synthesis by chemical vapor deposition have been hampered by the lack of a quantitative understanding of the gas-phase chemistry as well as the growth mechanism at the scale and quality required for applications. Indeed, interdependent variables and processes make the process optimization complex and successful scale-up remains difficult due to the absence of a validated methodology that bridges the gap between the molecular and macroscopic length scales over a wide range of time scales.

The literature contains few studies involving plasma diagnostics and CVD modeling. Shivkumar et al. proposed a numerical model to simulate hydrogen plasma inside a microwave plasma CVD cavity used for graphene growth [77]. Their model solves fully coupled Maxwell and heat-transfer equations to predict the electric field, electron number density, electron temperature, and gas temperature in a $2 \mathrm{D}$ axisymmetric configuration. The predicted gas temperatures were in good agreement with the hydrogen temperatures experimentally measured using optical emission spectroscopy (OES) techniques [77]. Kim et al. proposed a modeling approach to correlate the CVD graphene growth of methane on copper to the substrate temperature and 
partial gas pressure [82]. The model predicts the final surface coverage of graphene. Trinsoutrot $e t$ al. proposed a chemical mechanism for methane pyrolysis on copper foil within a computational fluid dynamics (CFD) model to investigate the role of the gas phase in graphene formation [79]. The team led by Prof. E. Tartarova studied the synthesis of freestanding graphene sheets from the decomposition of ethanol vapor in atmospheric-pressure microwave argon plasma $[80,81]$. Their model considers the decomposition of ethanol/argon/hydrogen in microwave plasma through 57 species and 394 homogeneous reactions. The model resolution provides information about the precursor's fluxes toward growing solid carbon nuclei. Considering the diffusion of carbon species into colder zones of the plasma reactor, the formation of solid carbon nuclei in the colder nucleation zones of the plasma reactor was analyzed from the model results. A correlation between $\mathrm{C}_{2}$ radicals and $\mathrm{C}$ atom number densities and the $\mathrm{sp}^{3} / \mathrm{sp}^{2}$ ratio in the freestanding graphene sheets was observed with the hypothesis that the assembly of planar $\mathrm{sp}^{2}$ carbons is dominated by the presence of $\mathrm{C}_{2}$ radicals [80]. To explain the temperaturedependent graphene growth kinetics in pulsed CVD on Ni film substrates, Puretzky et al. developed a model involving generation of carbon atoms on the metal surface resulting from the feedstock gas pulse, carbon diffusion in the bulk of the film, and diffusion to surface defects or graphene crystallites within a shallow subsurface layer of the film [82]. In situ optical diagnostics during graphene deposition allowed the activation energies for graphene nucleation $(1.6 \pm 0.2 \mathrm{eV})$ and growth $(0.9 \pm 0.1 \mathrm{eV})$ to be derived. Finally, Al-Shurman $e t$ al. used COMSOL Multiphysics software to simulate inward and outward carbon diffusion in a Ni film and the number of achieved graphene layers $[83,84]$. Despite all of the aforementioned studies, a detailed model of the mechanism of CVD graphene growth has not been developed. Indeed, achieving a reliable description of graphene growth requires solving self-consistently nonequilibrium energy and species mass transport equations with detailed plasma chemistry, including radicals and excited species. Interaction of plasma species with solid surfaces must also be considered. These self-consistent models are more time consuming and less suitable for describing many plasma species in complex plasma chemistries. For these reasons, we propose in this paper to develop two modeling approaches to assess the intrinsic parameters of graphene PECVD over cobalt and copper catalysts. As a first approximation, the plasma will be described by spatially averaged (bulk) properties; a selfconsistent two-dimensional model 2D will then be used to determine auto-coherently the electromagnetic field, gas and electron temperatures, heavy species, and electron and ion density distributions in the reactor. Both models are validated by OES. 


\section{EXPERIMENTAL}

\section{A. Experimental setup}

\section{Investigated plasma reactor and process parameters}

For graphene synthesis, we used a $10 \mathrm{~cm}$ diameter silica bell jar PECVD reactor activated by a microwave electric field, as illustrated in Figure 1. The input gases $\mathrm{CH}_{4} / \mathrm{H}_{2} / \mathrm{Ar}$ (N55 purity for $\mathrm{H}_{2}$ ) with mass flow rates controlled electronically were injected into the reactor and exited via the reactor pumping system. The copper or cobalt substrate $\left(1 \times 1 \mathrm{~cm}^{2}\right.$ in size and $125 \mu \mathrm{m}$ in thickness, $99.9 \%$ purity for cobalt; $99.95+\%$ purity for copper) was placed on a resistive molybdenum substrate holder heated by an electric current flowing from an external generator through a graphite resistor placed below the molybdenum holder. The heating unit was designed with a proportional-integral-derivative (PID) controller to automatically adjust the current flow with respect to the susceptor temperature measured with a feedback thermocouple embedded in the center of the susceptor. During all of the experiments, the substrate temperature was monitored by a dual-wavelength optical pyrometer (IMPAC, IGAQ-10) between 973 and $1163 \mathrm{~K}$, and we considered this temperature to be the actual substrate/deposition temperature for graphene synthesis. The reactor was powered by a $1.2 \mathrm{~kW}$ SAIREM microwave generator operating at $2.45 \mathrm{GHz}$. The system enabled independent control of the microwave power, gas flow rates, and substrate temperature. The total input power was varied with the pressure simultaneously to maintain a constant plasma volume. The electromagnetic waves were generated, guided in a rectangular wave guide and applied inside the cavity delimited by a Faraday cage through an antenna. The short-circuit piston at the end of the wave guide helped to create stationary waves and to situate the maximum of the electric field near the substrate. Efficient operation was assumed with good microwave coupling and minimal radial diffusion to the quartz enclosure, thereby leading to greater discharge stability and better plasma uniformity. Energy transfer started from the free electrons, which were accelerated in the electric field and formed high-energy electrons $(15,000-20,000 \mathrm{~K})[85]$. These electrons heated the gas by vibrational and rotational excitation of the molecules. The density of the gas being relatively high, neutral collisions were sufficiently frequent that the resultant excited molecules could transfer part of their energy to the other molecules and to the wall. The system became thermally activated, and other discharge processes could occur. Inelastic collisions between high-energy electrons and neutral molecules, such as electron-impact ionization and molecular dissociation, generated radical neutrals and ions. Electron impact ionization helped sustain the discharge, and molecular dissociation created free radicals that contributed to the graphene deposition process. The graphene growth rate and quality depended 
on the number density of atomic hydrogen and the concentration of carbon precursors on the surface of the substrate, which in turn depended on the discharge and operating conditions.

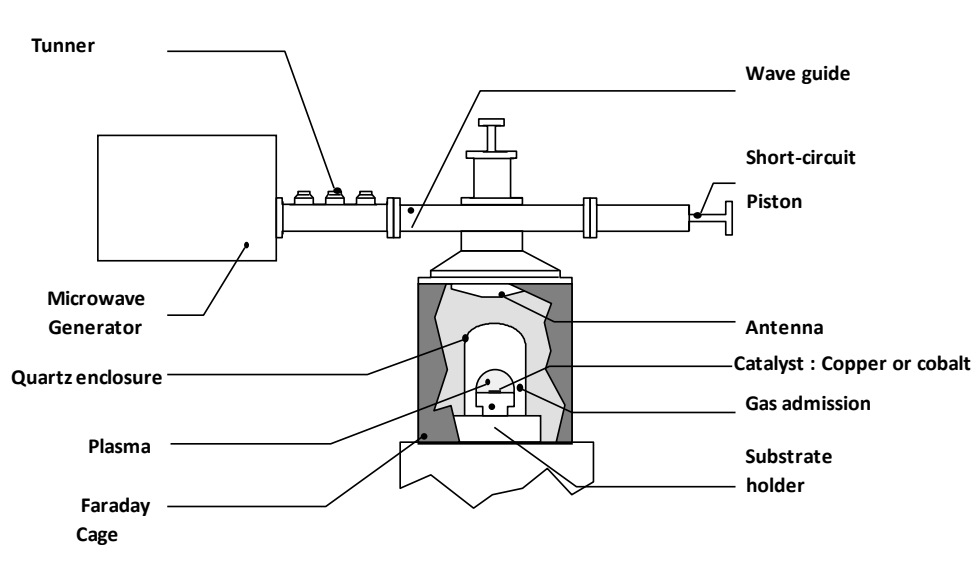

(a)

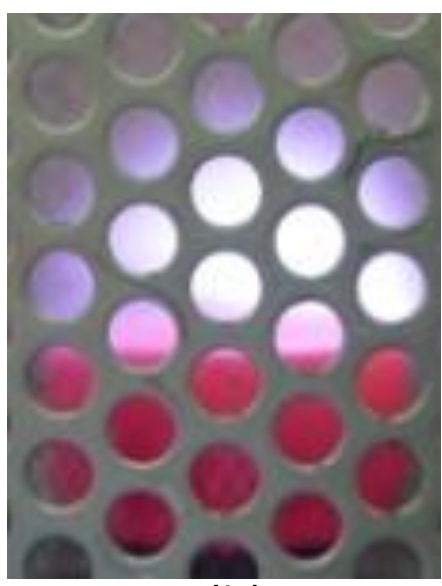

(b)

Figure 1. PECVD Bell jar reactor used for graphene growth: (a) scheme and (b) picture of the plasma on the substrate holder during graphene growth.

In the specific graphene growth conditions, the input power and pressure were varied simultaneously to maintain the plasma diameter at approximately $5 \mathrm{~cm}$. For the present reactor, increasing the microwave power at constant pressure showed marginal increase in power density leading to the expansion of plasma. In our case, the growth process is based on the cobalt- or copper-catalyzed decomposition of the hydrogen-methane mixture followed by high-temperature carbon saturation of the cobalt bulk substrate or surface nucleation in the case of the copper substrate. During cooling of the cobalt substrate, the solubility of carbon in the cobalt decreases, and a thin film of carbon is thought to precipitate from the surface. In the opposite situation, when the copper is used, graphene growth occurs on the surface by nucleation followed by domain growth. The substrate temperature, methane flow rate, deposition time, and microwave power are assumed to affect the number of graphene layers and the defect density.

\section{Optical emission spectroscopy}

To better understand and optimize the graphene growth conditions, the PECVD system was combined with the OES setup shown in Figure 2. The plasma emits radiation primarily from atomic and molecular hydrogen lines and from the $\mathrm{C}_{2}$ Swan band. The emission intensity signal from the plasma is collected using an optical fiber with a plasma emissive cylinder of $1 \mathrm{~mm}$ diameter across a line of sight passing through the window 
of the observation and connected to a spectrometer with a $0.5 \mathrm{~m}$ focal length and a $1800 \mathrm{gr} / \mathrm{mm}$ grating (Acton SP-2500i) onto which an intensified charged coupled device camera was mounted (Princeton Instruments PIMAX 2). A computer connected to the spectrometer was used for data acquisition with a typical collection time of $10 \mathrm{~ms}$. The spectrometer is calibrated using a UV lamp.

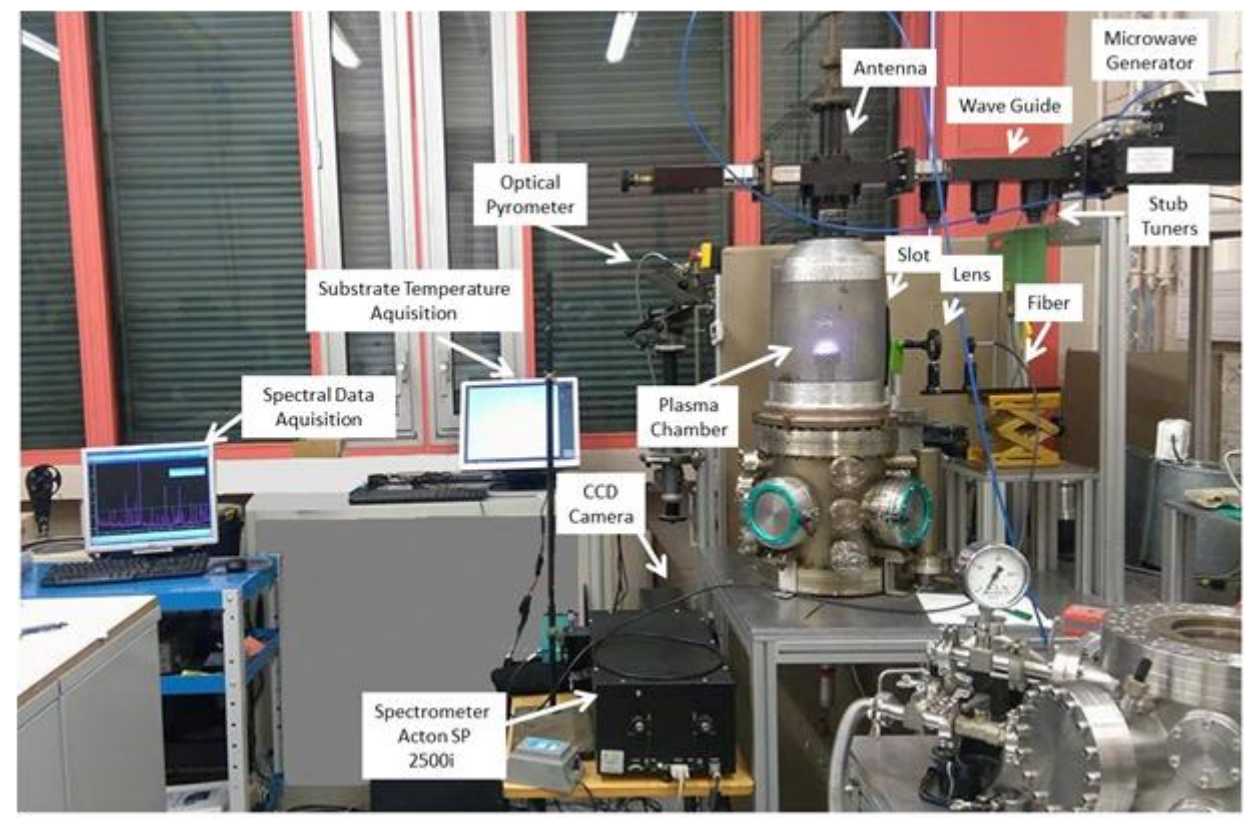

Figure 2. Photography of the PECVD reactor with the optical emission spectroscopy (OES) setup.

As shown in Figure 3, the optical fiber was first positioned in the middle of the plasma at $\sim 1.7 \mathrm{~cm}$ from the substrate; a plate allows the fiber to be moved along the vertical axis of the reactor. Various location points along axial directions $\sim 1 \mathrm{~mm}$ near the substrate and $2.5 \mathrm{~cm}$ from the substrate toward the plasma were measured in several spectral regions, including the $\mathrm{H}_{2}$ Fulcher- $\alpha$ band and the hydrogen atomic lines $\mathrm{H}_{\alpha}$ and $\mathrm{H}_{\beta}$, under different plasma conditions.

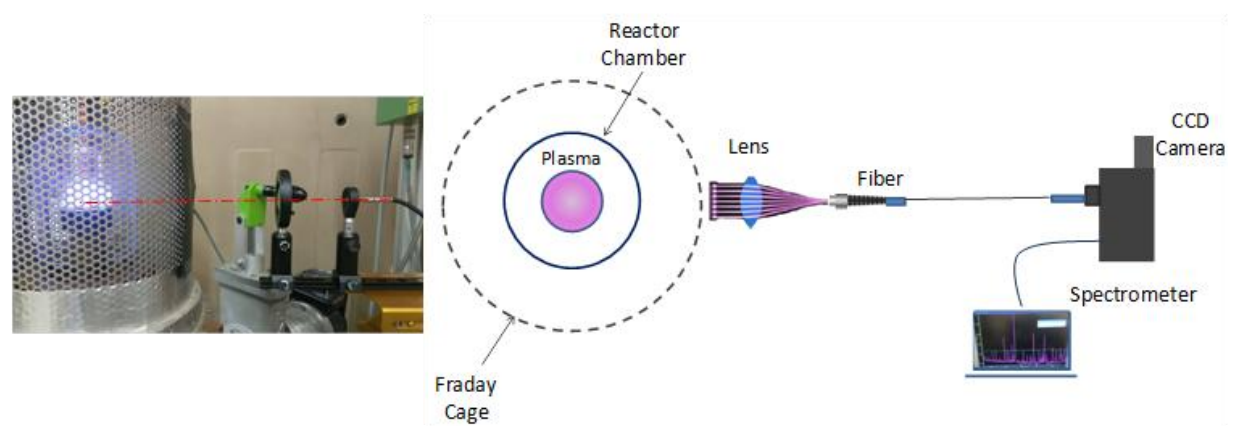

Figure 3. Photography (left) and top view scheme (right) of the optical emission spectroscopy (OES) setup.

\section{B. Plasma optical emission spectroscopy}


The emission of light from a plasma originates from many microscopic processes and gives rise to specific spectral features, such as atomic lines, molecular bands, and continuum emission. A certain amount of these species is electronically excited to higher energy levels. In the process of returning to their ground state, energy is emitted in the form of light that can be detected by an optical multichannel analyzer. Since atoms, ions and molecules create a unique emission spectrum specific to each element, OES enables their identification. OES has the advantage of being noninvasive and has already been used to monitor the state of plasma in situ and to determine the concentration of the species and different plasma parameters, such as the electron densities and temperatures of diamond [85-93], carbon nanotubes [94] and, more recently, graphene [77]. Since an important step in achieving control of defect-free and few-layers graphene synthesis involves understanding the role of plasma properties, OES can help to identify the species responsible for graphene growth. Rotational and translational temperatures related to the kinematics of the particles in the plasma governs the chemical kinetics of the CVD processes and thus critically affects the species concentration and the growth rates on the substrate. In addition, because atomic hydrogen is one of the most reactive species in the plasma, its relative concentration is critical for graphene growth. Emission from molecules is more complicated than that from atoms because it is affected by repulsive and attractive forces present between the constituent atoms as well as by vibrational and rotational motion of the molecules.

\section{Determination of the $\mathrm{H}_{2}$ rotational temperature}

To determine the $\mathrm{H}_{2}$ rotational temperature, we measured the optical emission spectrum from the Fulcher- $\alpha$ Q-branch of the $d^{3} \Pi_{\mathrm{u}}(0) \rightarrow a^{3} \sum_{g}^{+}(0)$ transitions. The choice of the Q-branch rather than the $G^{1} \sum_{g}^{+}(0)$ $\rightarrow B^{1} \sum_{u}^{+}(0)$ R-branch is justified by the absence of perturbations or overlap with other transitions in the Qbranch [95]. The Fulcher- $\alpha$ system is suitable for measuring the gas temperature on the basis of two main assumptions: (i) The $d^{3} \Pi_{\mathrm{u}}^{-}$excited state is primarily populated by electronic excitation from the ground state with $\Delta \mathrm{N} \leq 1$, with a rate coefficient obtained from an adiabatic approximation and (ii) the distribution of the population of the ground $\mathrm{X}^{1} \Sigma_{\mathrm{u}}^{+}, v=0$ electronic-vibrational state can be described by Boltzmann's law, and the rotational temperature of the ground state is equal to the neutral gas temperature [96]. However, as demonstrated by Tomasini et al., the ground-state rotational temperature is similar to the plasma translational temperature for hydrogen plasma operating at a 0.5-1 Torr reactor pressure, 200-750 W plasma power and 5 sccm $\mathrm{H}_{2}$ flow rate [97]. Because the purpose of this work is to establish a reliable and accurate methodology for measuring the gas 
temperature in a microwave plasma under graphene growth conditions, we will assume that the rotational temperature is representative of the gas temperature for two sets of experiments. In one set, pure $\mathrm{H}_{2}$ plasma is used at different microwave powers; in the other set, a $\mathrm{CH}_{4} / \mathrm{H}_{2}$ mixture gas is used to grow graphene under four optimized conditions based on our previous Taguchi design study combining four growth parameters [76]. Since the transition energy is a characteristic of the species, the central wavelength $\lambda$ is an identifier of the radiating particle. Hence, the rotational temperature was calculated from the measurements of relative intensities of rotational lines within a single vibrational band that follows a Boltzmann distribution. The intensity of the emitted radiation from an upper excited quantum state $\left(n^{\prime}, v^{\prime}, J^{\prime}\right)$ to a lower excited quantum state (n", v", J") depends strongly on the plasma parameters and is given by [94,98]:

$I=C_{1} v^{4} q_{v \prime v^{\prime \prime}} \exp \left(-\frac{E_{v^{\prime}}}{k_{B} T_{v}}\right) S_{J^{\prime} J^{\prime \prime}} \exp \left(-\frac{E_{J^{\prime}}}{k_{B} T_{r o t}}\right)$

where $\mathrm{I}$ is the intensity, $\mathrm{C}_{1}$ is a constant for the particular electronic state, $\mathrm{v}$ is the transition frequency, $\mathrm{q}_{\mathrm{v}^{\prime} \mathrm{v}^{\prime \prime}}$ is the Franck-Condon factor, $\mathrm{T}_{\mathrm{v}}$ and $\mathrm{T}_{\mathrm{rot}}$ are the vibrational and rotational temperatures, respectively, $\mathrm{E}_{\mathrm{v}^{\prime}}$ and $\mathrm{E}_{\mathrm{J}^{\prime}}$ are the vibrational and rotational energies of the upper excited quantum state, respectively, $\mathrm{k}_{\mathrm{B}}$ is Boltzmann's constant, $\mathrm{S}_{\mathrm{J}^{\prime} \mathrm{J}}$ is the Hönl-London factor, $\mathrm{v}^{\prime}$ and $\mathrm{v}^{\prime \prime}$ are the vibrational quantum numbers of the upper and lower transition levels, respectively, and $\mathrm{J}^{\prime}$ and $\mathrm{J}^{\prime \prime}$ are the rotational quantum numbers of the upper and lower emission levels, respectively [94,98]. For a rotational transition within a particular electronic state and vibrational band that follows a Boltzmann distribution, the emission intensity can be rewritten from Eq. (1) for a given wavelength $\lambda$ as [77]

$I \propto \frac{S_{J^{\prime} J^{\prime \prime}}}{\lambda^{4}} \exp \left(-\frac{E_{J^{\prime}}}{k_{B} T_{\text {rot }}}\right)$

Hence, in the so-called Boltzmann plot, the quantity $\ln \left(\mathrm{I} \lambda^{4} / \mathrm{S}_{\mathrm{J}^{\prime} \mathrm{J}}\right)$ is plotted vs. the upper state rotational energy $\mathrm{E}_{\mathrm{J}}$ for several measured transitions. A straight-line fit can be drawn through the data, and the rotational temperature $\mathrm{T}_{\text {rot }}$ can be extracted from the slope of this line, which is equal to $\left(-1 / k_{B} T_{\text {rot }}\right)$. Therefore, the $\mathrm{H}_{2}$ rotational temperature $\mathrm{T}_{\text {rot }}$ can be deduced from the $\mathrm{H}_{2}$ optical emission spectrum and the small deviation from the straight-line distribution is an indication of the Boltzmann equilibrium of the excited states. For the Q-branch rotational lines, wavelengths and Hönl-London factors were obtained from the literature [94,99,100].

\section{Determination of the atomic hydrogen concentration via actinometry}


Optical emission actinometry has been proposed as one of the best available experimental techniques for monitoring ground-state relative concentrations of $\mathrm{H}$ radicals $(\mathrm{n}=1)$ from emission intensity measurements in a microwave PECVD reactor [91]. The principle consists of normalizing the radical emission intensity to that from an inert gas acting as an actinometer [101]. Gicquel et al. proposed using this plasma diagnostic to measure relative concentrations of $\mathrm{H}(\mathrm{n}=1)$ atoms in microwave PECVD diamond, typically at a pressure of 20 Torr and a plasma power of $600 \mathrm{~W}[85,89]$. Since one on the most important parameters in graphene synthesis is the atomic hydrogen concentration, we propose extending this technique to graphene growth to provide a better understanding of $\mathrm{H}$ atom chemistry. The method consists of adding a small, known amount of an inert tracer (here, argon) such that the plasma is neither disturbed nor modified. The choice of argon is justified by its radiative states with excitation thresholds similar to those of $\mathrm{H}$ atoms. Then, by comparing the intensities of specific emissions of the actinometer and of the $\mathrm{H}$ radical, the concentration of the latter can be deduced from the relation:

$\frac{[H]}{[A r]}=\frac{x_{H}}{x_{A r}}=k(F D E E$, quenching terms $) \cdot \frac{I_{H_{\alpha}}}{I_{A r^{*}}}$

where $[H]$ and $[A r]$ are the concentrations of electronic ground state $\mathrm{H}$ atoms and actinometer species $\mathrm{Ar}$ $\left(\right.$ mol. $\left.\mathrm{m}^{-3}\right)$, respectively, $I_{H}$ and $I_{A r *}$ are the ratios of emission intensities of the excited $\mathrm{H}$ species and excited actinometer species $\left(\mathrm{W} \cdot \mathrm{m}^{-3}\right)$, respectively, and $k$ is the proportionality constant that links the atomic hydrogen ground state concentration to the emission intensities and depends on the electron temperature and the collision quenching terms. Argon gas with a flow rate of $3 \mathrm{sccm}$ was introduced into the hydrogen plasma. As suggested by Gicquel et al. [85,89], we focused on the H Balmer- $\alpha(651 \mathrm{~nm})$ and $\operatorname{Ar}(750.4 \mathrm{~nm})$ emission lines because they give similar thresholds and electron temperature $\left(\mathrm{T}_{\mathrm{e}}\right)$-dependent electron impact excitation cross sections for forming $H(n=3)$ and $\left.\operatorname{Ar}\left(3 s^{2} 3 p^{5}\left[{ }^{2} p^{0}{ }_{1 / 2}\right)\right] 4 p\right)$, denoted $\operatorname{Ar}(4 p)$. In Table 1 are shown the species, upper and lower level assignments, transition wavelengths and the energies for tracers that we monitored during the OES studies.

Table 1. Transition wavelengths, upper and lower level assignments of the measured species and energies for the tracers.

\begin{tabular}{cccccccccc}
\hline Species & $\begin{array}{c}\lambda \\
(\mathrm{nm})\end{array}$ & $\begin{array}{c}\text { Upper } \\
\text { level }\end{array}$ & $\begin{array}{c}\text { Energy } \\
(\mathrm{eV})\end{array}$ & $\begin{array}{c}\text { Lower } \\
\text { level }\end{array}$ & $\begin{array}{c}\text { Energy } \\
(\mathrm{eV})\end{array}$ & $\begin{array}{c}\sigma_{\mathrm{H} \alpha / \mathrm{H} 2} \\
\left(\AA^{2}\right)\end{array}$ & $\begin{array}{c}\sigma_{\mathrm{H \alpha} / \mathrm{H}} \\
\left(\AA^{2}\right)\end{array}$ & $\begin{array}{c}\sigma_{\mathrm{Ar} * / \mathrm{H} 2} \\
\left(\AA^{2}\right)\end{array}$ & $\begin{array}{c}\sigma_{\mathrm{Ar} * / \mathrm{H}} \\
\left(\AA^{2}\right)\end{array}$ \\
\hline$H_{\alpha}$ & 656.3 & $\mathrm{n}=3$ & 12.10 & $\mathrm{n}=2$ & 10.20 & 58 & 46 & - & - \\
$A r_{750}$ & 750.4 & $2 \mathrm{p}_{1}$ & 13.48 & $1 \mathrm{~s}_{2}$ & 11.86 & - & - & 65 & 53 \\
\hline
\end{tabular}

The production of $\mathrm{H}(\mathrm{n}=3)$ and $\operatorname{Ar}(4 \mathrm{p})$ atoms occur via electron impact excitation from ground states, and their consumption is induced by radiative decay and quenching for $\mathrm{H}(\mathrm{n}=3)$ and by radiative de-excitation and 
quenching for $\operatorname{Ar}(4 \mathrm{p})$. The net balance of production and consumption leads to the following expression for the relative concentrations of ground state $\mathrm{H}(\mathrm{n}=1)$ atoms:

$\frac{[H]}{[A r]}=\frac{x_{H}}{x_{A r}}=F \frac{k_{e}^{A r^{*}}}{k_{e}^{H \alpha}} \frac{v_{A r^{*}}}{v_{H_{\alpha}}} Q_{T} \frac{I_{H a}}{I_{A r}}$

where $\mathrm{I}_{\mathrm{H} \alpha}$ and $\mathrm{I}_{\mathrm{Ar}}$ are the $\mathrm{H}(\mathrm{n}=3)$ and $\operatorname{Ar}(4 \mathrm{p})$ emission intensities, respectively, $k_{e}^{H_{\alpha}}$ and $k_{e}^{A r^{*}}$ are the excitation rate constants for the transition $\mathrm{H}(\mathrm{n}=1) \rightarrow \mathrm{H}(\mathrm{n}=3)$ and the transition $\operatorname{Ar}(3 \mathrm{p}) \rightarrow \operatorname{Ar}(4 \mathrm{p})\left(\mathrm{m}^{-3} \cdot \mathrm{s}^{-1}\right)$,

respectively, $v_{A r^{*}}$ and $v_{H_{\alpha}}$ are the de-excitation frequencies for the $H_{\alpha}$ and $A r^{*}$ transitions $\left(\mathrm{s}^{-1}\right)$, respectively, $F$ is an optical device factor, and $Q_{T}$ accounts for the radiative and quenching processes. When the emissive volume and the optical device factor are considered, the emission intensity of $H_{\alpha}$ is given by the relation:

$I_{H_{\alpha}}=\frac{n_{H} k_{e}^{H} n_{e}}{k_{r}+n_{H_{2}} k_{Q_{H_{\alpha} / H_{2}}}+n_{H} k_{Q_{H_{\alpha} / H}}} \cdot A_{32} \cdot h \cdot v_{H_{\alpha}} V_{e m} \cdot F\left(\lambda_{H_{\alpha}}\right)$

where $A_{32}$ and $A_{31}$ are constants obtained from the Einstein coefficients for spontaneous radiative de-excitation, and the total radiative rate constant is equal to $k_{r}=\left(A_{32}+A_{31}\right)=9.810^{7}\left(\mathrm{~s}^{-1}\right) ; k_{Q_{H_{\alpha} / H_{2}}}$ and $k_{Q_{H_{\alpha} / H}}$ are the quenching rate constants of $H_{\alpha}$ by the $\mathrm{H}_{2}$ molecules and by $\mathrm{H}$ atoms $\left(\mathrm{m}^{3} \cdot \mathrm{s}^{-1}\right)$ and are equal to $\mathrm{v}_{H / H_{2}} \cdot \sigma_{H_{\alpha} / H_{2}}$ and $\mathrm{v}_{H / H} \cdot \sigma_{H_{\alpha} / H}$, respectively. Here, the terms $\mathrm{v}_{H / H_{2}}$ and $\mathrm{v}_{H / H}$ are the relative mean velocities of $H_{\alpha}$ atoms and $\mathrm{H}_{2}$ molecules and $H_{\alpha}$ and $\mathrm{H}$ atoms $\left(\mathrm{m} . \mathrm{s}^{-1}\right)$, respectively, $\sigma_{H_{\alpha} / H_{2}}$ and $\sigma_{H_{\alpha} / H}$ in $\AA^{2}$ are the quenching cross sections of $H_{\alpha}$ by the $\mathrm{H}_{2}$ molecules and by $\mathrm{H}$ atoms, respectively. The relative mean velocity between species $\mathrm{X}$ and $\mathrm{Y}$ is calculated using the following equation:

$\mathrm{v}_{X / Y}=\sqrt{\frac{8 k_{B} T}{\pi \mu}}$

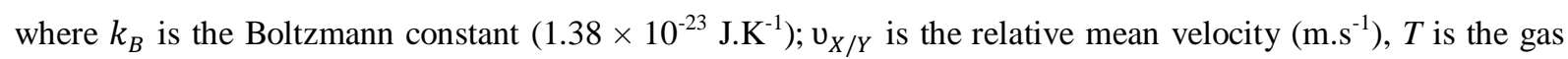
temperature $(\mathrm{K})$ and $\mu$ is the reduced mass of species $\mathrm{x}$ relative to species $\mathrm{y}(\mathrm{kg})$.

For the argon excitation process, we have

$I_{A r^{*}}=\frac{n_{H} k_{e}^{A r^{*}} n_{e}}{k_{r}+n_{H_{2}} k_{Q_{A r^{*} / H_{2}}}{ }^{+n_{H} k_{Q_{A r^{*} / H}}}} \cdot A_{44} \cdot h \cdot v_{A r^{*}} V_{e m} \cdot F\left(\lambda_{A r^{*}}\right)$ 
where $k_{Q_{A r^{*} / H_{2}}}$ and $k_{Q_{A r^{*} / H}}$ are the quenching terms of $A r^{*}$ by molecular hydrogen and atomic hydrogen, respectively, and they are equal to $\mathrm{v}_{A r / H_{2}} \cdot \sigma_{A r^{*} / H_{2}}$ and $\mathrm{v}_{A r / H} \cdot \sigma_{A r^{*} / H}$. The terms $\mathrm{v}_{A r / H_{2}}$ and $\mathrm{v}_{A r / H}$ are the relative mean velocities between $\mathrm{Ar}$ and $\mathrm{H}_{2}$ and $\mathrm{H}$ atoms $\left(\mathrm{m} . \mathrm{s}^{-1}\right)$, respectively, $\sigma_{A r^{*} / H_{2}}$ and $\sigma_{A r^{*} / H}$ are the quenching cross sections expressed in $\AA^{2}$, and $A_{44}$ is the Einstein coefficient for the spontaneous transition $\operatorname{Ar}(4 \mathrm{p}) \rightarrow \operatorname{Ar}(4 \mathrm{~s})$ and is equal to $4.27 \times 10^{7} \mathrm{~s}^{-1}$.

Finally, by considering a constant emissive volume, we can determine the ratio of the emission intensities of hydrogen and argon using the following equation:

$n_{H}=\frac{k_{e}^{A r^{*}}}{k_{e}^{H}} \cdot \frac{v_{A r^{*}}}{v_{H_{\alpha}}} \cdot Q_{T} \cdot F \cdot \frac{I_{H_{\alpha}}}{I_{A r^{*}}} \cdot n_{A r}$

with

$F=\frac{F\left(\lambda_{A r^{*}}\right)}{F\left(\lambda_{H_{\alpha}}\right)} \quad$ and $\quad Q_{T}=\frac{1+P T^{-1 / 2}\left[0.132 \sigma_{H_{\alpha} / H_{2}} x_{H_{2}}+0.152 \sigma_{H_{\alpha} / H}\left(1-x_{H_{2}}\right)\right.}{1+P T^{-1 / 2}\left[0.162 \sigma_{A r^{*} / H_{2}} x_{H_{2}}+0.226 \sigma_{A r^{*} / H}\left(1-x_{H_{2}}\right)\right.}$

where $T$ is the gas temperature (K); $P$ is the pressure expressed in hPa and $X_{\mathrm{H}_{2}}$ is the molecular hydrogen mole fraction.

\section{PLASMA MODELING}

To determine the effect of kinetics, thermodynamic driving forces and fluid flow conditions on graphene deposition, a CVD multiphysical process is solved by varying the chemical and geometrical complexity, as schematically shown in Figure 4. Different modeling approaches can be investigated, including multidimensional 0D, 1D and 2D simulations. 


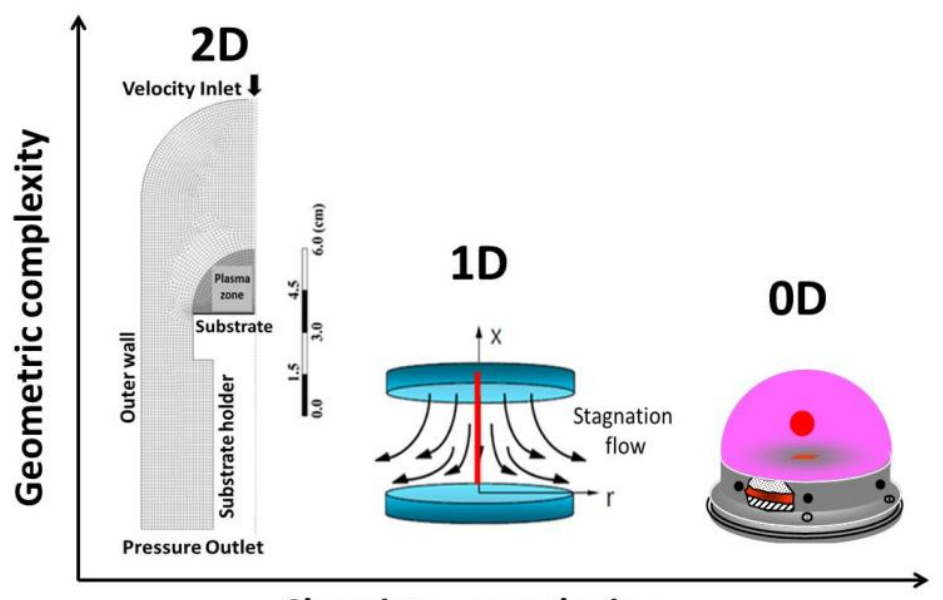

Chemistry complexity

Figure 4. Modeling approaches in CVD.

The 0D model extends the classical chemistry formulation to nonequilibrium plasma reactors that include gas, electron and vibrational temperatures with sophisticated gas-phase chemistry and detailed power deposition with inelastic and elastic collision losses by assuming the electron energy distribution function (EEDF). This model, was already validated in our group for pure hydrogen plasma used for CVD diamonf through measurements of rotational and vibrational modes as well $\mathrm{H}$-atom mole fraction via optical emission spectroscopy, two-photonallowed transition laser-induced fluorescence (TALIF), and coherent anti-stokes Raman spectroscopy (CARS) [102]. All these measurements was performed in the same reactor geometry used for diamond growth in conditions close to those studied in the present work for graphene (i.e. Plasma radius $\mathrm{R}=2.5 \mathrm{~cm}$, Microwave power $\mathrm{Pmw}=600 \mathrm{Watt}$ and pressure $\mathrm{P}=25 \mathrm{mbar}$ ). Our group has also developed an intermediate approach for graphene growth by using a 1D model with only neutral species and detailed surface chemistry. This approach can be extended to 2D-3D with an assumed MW power density distribution obtained experimentally. The limitation of this approach is that the transfer of energy between the electrons and heavy species is neglected, and, for the same MW power density, the gas temperatures are usually overestimated. More importantly, because the methane/hydrogen system is sensitive to gas temperature, this approach cannot capture the conditions of graphene growth satisfactorily. This limitation can be overcome by considering an extended chemistry scheme that includes charged species; however, due to computational limitations, the chemistry scheme must be reduced compared with that of the 0D model. Furthermore, to achieve a more realistic MW power density distribution, a self-consistent model can be used to couple the electromagnetic Maxwell's equations and the plasma. In our work, we will use the $0 \mathrm{D}$ model with detailed chemistry and the 2D axisymmetric self-coherent model with reduced chemistry to study the multiphysics. 
Because the transport of $\mathrm{H}$ atoms is diffusion-limited and the boundary layer thickness $\delta$ depends on the spatial power density distribution in the plasma, a 2D axisymmetric auto-coherent model [103] has been used to make a self-consistent simulation of microwaves (MWs) and plasma. The model consists of a plasma module and a microwave module, which are solved iteratively until convergence of the plasma variables and microwave power density is achieved. The microwave module computes the time-averaged microwave power density $\mathrm{P}_{\mathrm{abs}}$ from the densities of electrons and heavy species, which are determined from the solution of the plasma module. The plasma module solves for the chemistry, transport and energy of electrons and heavy species using a finite volume approach, whereas the MW module solves Maxwell's equations and high-frequency electron momentum equations using the finite difference time domain method. The self-consistent model has been explained in detail elsewhere [103,104], and a brief summary is provided here. The plasma module of the self-consistent model consists of the solution to the total energy equation, electron energy equation, and species equations along with hydrodynamic equations and are solved using finite volume methods. Unlike the (0D) model, the nonequilibrium plasma conditions are represented by a two-temperature model in which the electron is assumed to be at temperature $T_{e}$ and the heavy species are at temperature $T$, which are defined as

$$
\begin{aligned}
& T_{e}=\frac{h_{e}-h_{e}^{0}}{\bar{c}_{p e}} \\
& T=\frac{h_{t}-Y_{e} h_{e}-\sum Y_{i} h_{i}^{0}}{\bar{c}_{p}\left(1-Y_{e}\right)}
\end{aligned}
$$

Here, $h_{e}$ and $h_{t}$ are the specific enthalpy of electrons and the total enthalpy, respectively, and $h_{i}{ }^{0}$ is the specific enthalpy of formation of species i. The total energy conservation equation includes the transport terms in addition to the source terms in the OD model and can be written as

$\frac{\partial \mathrm{h}_{\mathrm{t}}}{\partial \mathrm{t}}+\nabla \cdot\left(\rho \mathrm{h}_{\mathrm{t}}\right)=\nabla\left\{\lambda_{\mathrm{g}} \nabla \mathrm{T}+\lambda_{\mathrm{e}} \nabla \mathrm{T}_{\mathrm{e}}-\sum \mathrm{J}_{\mathrm{i}} \mathrm{h}_{\mathrm{i}}\right\}+\mathrm{P}_{\mathrm{abs}}$

where $\mathrm{t}$ is time, $\mathrm{u}$ is the bulk velocity, and $\lambda_{\mathrm{g}}, \lambda_{\mathrm{e}}$ and $\mathrm{J}_{\mathrm{i}}$ are the gas thermal conductivity, electron thermal conductivity and the mass diffusion flux of species i respectively. Using Fick's law, the mass diffusion flux is calculated as $\mathrm{J}_{\mathrm{i}}=-\mathrm{D}_{\mathrm{i}} \rho \nabla \mathrm{Y}_{\mathrm{i}}$, where $\mathrm{D}_{\mathrm{i}}$ is the mass diffusivity of the species. The resolution of $\mathrm{T}_{\mathrm{e}}$ is obtained by solving the energy equations for electrons, which can be written as

$\frac{\partial \rho \mathrm{Y}_{\mathrm{e}} \mathrm{h}_{\mathrm{e}}}{\partial \mathrm{t}}+\nabla \cdot\left(\rho \mathrm{Y}_{\mathrm{e}} \mathrm{uh} \mathrm{e}\right)=\nabla\left\{\lambda_{\mathrm{e}} \nabla \mathrm{T}_{\mathrm{e}}-\mathrm{J}_{\mathrm{e}} \mathrm{h}_{\mathrm{e}}\right\}+\mathrm{P}_{\mathrm{abs}}-\mathrm{Q}_{\mathrm{ev}}-\mathrm{Q}_{\mathrm{te}}-\mathrm{Q}_{\mathrm{ei}}-\mathrm{Q}_{\mathrm{ed}}$

Note that $\mathrm{Q}^{1 \mathrm{v}}{ }_{\mathrm{ev}}$ is not considered for the self-consistent model. The heavy species temperature $\mathrm{T}$ is thus determined by the difference between the total and electron energy equations.

The species concentrations, except for electrons, are obtained by solving the species continuity equation given by 
$\frac{\partial \rho Y_{\mathrm{i}}}{\partial \mathrm{t}}+\nabla \cdot\left(\rho \mathrm{Y}_{\mathrm{i}} \mathrm{u}\right)=\nabla \mathrm{J}_{\mathrm{i}}+\omega_{\mathrm{i}}$

The plasma medium is assumed to be ambipolar; thus, the electron concentrations and electron mass flux rates are calculated from the balance of all ions. Along with the aforementioned equations, the total continuity and fluid momentum equations close the plasma module. All transport properties and reactions schemes are identical to those used elsewhere [103]. All of the equations are solved sequentially for every time step until steady-state conditions are achieved. The transient equations are integrated using implicit third-order backward formulas to handle the stiff chemistry. The microwave electromagnetic fields (E electric field and $\mathrm{H}$ magnetic field) are represented by Maxwell's equations and are calculated using the finite difference time domain method. Maxwell's equations are given by

$\nabla \times \mathrm{E}=-\mu \frac{\partial \mathrm{H}}{\partial \mathrm{t}}$

$\nabla \times H=\epsilon \frac{\partial E}{\partial \mathrm{t}}+\mathrm{J}$

As the MW radiation is TM mode, the magnetic fields along the radial $\mathrm{r}$ and axial $\mathrm{z}$ directions and the electric field along the $\Phi$ direction are zero and we are required to solve only three components of MW radiation: $\mathrm{E}_{\mathrm{r}}, \mathrm{E}_{\mathrm{z}}$ and $\mathrm{H}_{\Phi}$. The YEE iteration scheme is used, where the $\mathrm{E}$ and $\mathrm{H}$ are staggered and are solved at alternating half-time steps. The coupling between the plasma and MW is achieved through the high-frequency electron current density $\mathbf{J}$ and is obtained by solving the electron momentum equation

$\frac{d v_{e}}{d t}=\frac{e}{m_{e}} E-\sum v_{m, i} n_{i} v_{e}$

where $v_{\mathrm{e}}$ is the electron drift velocity, e and $\mathrm{m}_{\mathrm{e}}$ are the electron charge and mass, respectively, and $v_{\mathrm{m}, \mathrm{i}}$ and $\mathrm{n}_{\mathrm{i}}$ are the momentum frequency cross sections and the number density of species i, respectively. Equation (17) is integrated with the Crank-Nicholson method and is solved after every time step of Maxwell's equations. The current density due to the plasma source is simply given by $\mathrm{J}=-\mathrm{en}_{\mathrm{e}} \mathrm{v}_{\mathrm{e}}$. The $\mathrm{MW}$ module is solved for approximately 100 time cycles for a given plasma condition (electron and species concentrations assumed constant) and the average power density absorbed by the plasma is obtained by temporal averaging:

$\mathrm{P}_{\mathrm{abs}}=\frac{-1}{\delta \mathrm{T}} \int_{0}^{\delta \mathrm{T}} \mathrm{e}_{\mathrm{e}} \mathrm{Ev}_{\mathrm{e}} \mathrm{dt}$

The simulation is initiated by an initial assumption of $\mathrm{P}_{\mathrm{abs}}$ and the plasma module is solved to obtain the plasma conditions. The plasma conditions are input to the MW module and $\mathrm{P}_{\mathrm{abs}}$ is corrected. Thus, the plasma module and MW module are sequentially solved until $\mathrm{P}_{\mathrm{abs}}$ and a steady-state condition for the plasma are obtained. 


\section{RESULTS AND DISCUSSION}

\section{A. Experimental results}

We first conducted OES experiments in pure hydrogen by collecting spectra for various combinations of microwave power $\left(300 \leq \mathrm{P}_{\mathrm{mw}} \leq 580 \mathrm{~W}\right)$, pressure $(10 \mathrm{mbar} \leq \mathrm{P} \leq 25 \mathrm{mbar})$ and substrate temperature $\left(700^{\circ} \mathrm{C}\right.$ $\leq \mathrm{T}_{\mathrm{s}} \leq 980^{\circ} \mathrm{C}$ ). Different spectral regions, including the $\mathrm{H}_{2}$ Fulcher- $\alpha$ band, atomic lines of $\mathrm{H}_{\alpha}$ and $\mathrm{H}_{\beta}$ and atomic cobalt and copper lines, were acquired. From the analysis of the spectral features of the Q-branch of the $\mathrm{H}_{2}$ Fulcher band, we determined the rotational temperature. Using argon as an actinometer, we estimated the $\mathrm{H}-$ atom mole fractions. When the methane is added to the discharge as carbon feedstock, several dozen species are formed in the $\mathrm{C}-\mathrm{H}$ system, including $\mathrm{C}_{2}$ molecules.

For pure $\mathrm{H}_{2}$ plasma, measurements were run at conditions in which the size of the plasma based on its brightness luminescence is held constant as the pressure and microwave power are varied simultaneously under a constant $\mathrm{H}_{2}$ flow rate. The measurements were performed in the middle of the plasma at $\sim 1.7 \mathrm{~cm}$ from the cobalt substrate. This position corresponds to the maximum plasma temperature measured by spatially resolved twophoton-allowed transition laser-induced fluorescence (TALIF) and coherent anti-Stokes Raman spectroscopy (CARS) under the same conditions for pure hydrogen [102]. The operating conditions for these measurements are summarized in Table 2.

Table 2. Operating conditions for hydrogen plasma.

\begin{tabular}{ccccccccccccc}
\hline Experiment $^{\mathrm{a}}$ & 1 & 2 & 3 & 4 & 5 & 6 & 7 & 8 & 9 & 10 & 11 & 12 \\
\hline $\mathrm{P}_{\mathrm{mw}}(\mathrm{W})$ & 340 & 360 & 370 & 390 & 410 & 420 & 440 & 450 & 470 & 480 & 500 & 580 \\
Pressure $(\mathrm{mbar})$ & 10 & 11 & 12 & 13 & 14 & 15 & 16 & 17 & 18 & 19 & 20 & 25 \\
\hline
\end{tabular}

${ }^{a} 50 \mathrm{sccm} \mathrm{H}_{2}$ is used as a carrier gas for all the experiments

An example of the measured $\mathrm{H}_{2}$ Fulcher- $\alpha$ Q-branch spectrum is shown in Figure 5, where the Boltzmann plot corresponding to $\mathrm{Q}_{1}, \mathrm{Q}_{2}, \mathrm{Q}_{4}$ and $\mathrm{Q}_{6}$ selected rotational lines is shown in the inset. For these transitions, wavelengths and Hönl-London factors were obtained from the literature $[94,99,100]$. 


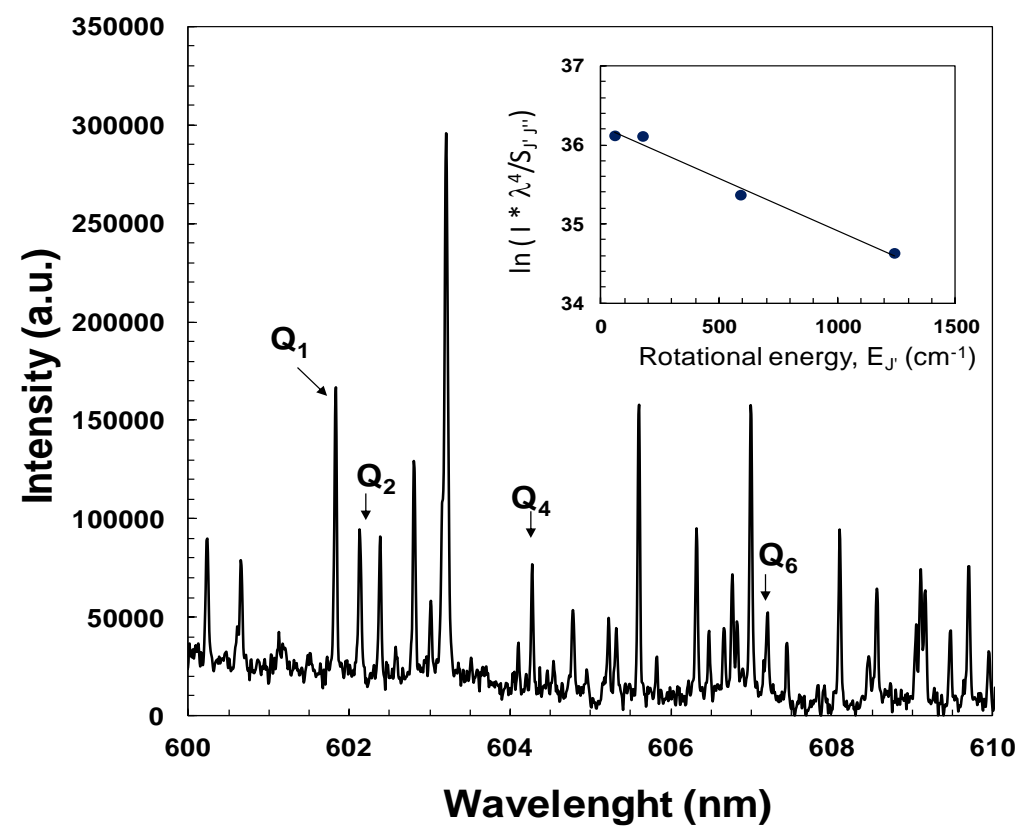

Figure 5. Example of measured $\mathrm{H}_{2}$ Fulcher- $\alpha$ Q-branch spectrum with indication to the selected rotational lines at microwave power of $390 \mathrm{~W}$ and total pressure of 13 mbar. The inset shows the corresponding Boltzmann plot.

The experimental $\mathrm{H}_{2}$ rotational temperatures shown in Figure 6 were obtained at $1.7 \mathrm{~cm}$ above the substrate by averaging four measurements for each point. In addition, the plasma intensity was recorded dynamically for up to $1 \mathrm{~s}$, thereby ensuring emission steady-state intensity within $\sim 5 \%$ as a nominal condition. As shown in Figure. 6, increasing the microwave power from 340 to $580 \mathrm{~W}$, as the pressure is increased simultaneously increases the $\mathrm{H}_{2}$ rotational temperatures from 930 to $1340 \mathrm{~K}$. This result is explained by two interdependent simultaneous effects: (i) because the gas temperature depends on the energy transferred from the electric field to the gas molecules by electrons during collisions, increasing the plasma power increases the gas temperature; (ii) increasing the pressure increases the collision frequency in the plasma and then the energy transfer between electrons and gas molecules. These results are in good agreement with the OES measurements of Shivkumar et al. in a similar microwave plasma CVD system used to grow carbon nanostructures [77]. Shivkumar et al. varied the pressure (10 Torr $\leq \mathrm{P} \leq 30$ Torr $)$ and the microwave power $\left(300 \leq \mathrm{P}_{\mathrm{mw}} \leq 700 \mathrm{~W}\right)$ separately. Their experimental results indicated a rotational temperature of $\sim 900 \mathrm{~K}$ at $300 \mathrm{~W}$ and 10 Torr and $1500 \mathrm{~K}$ at $700 \mathrm{~W}$ and 30 Torr, in good agreement with the results of the present work. In addition, they suggested that the gas temperature has weak dependence on power and very strong dependence on pressure [77]. 


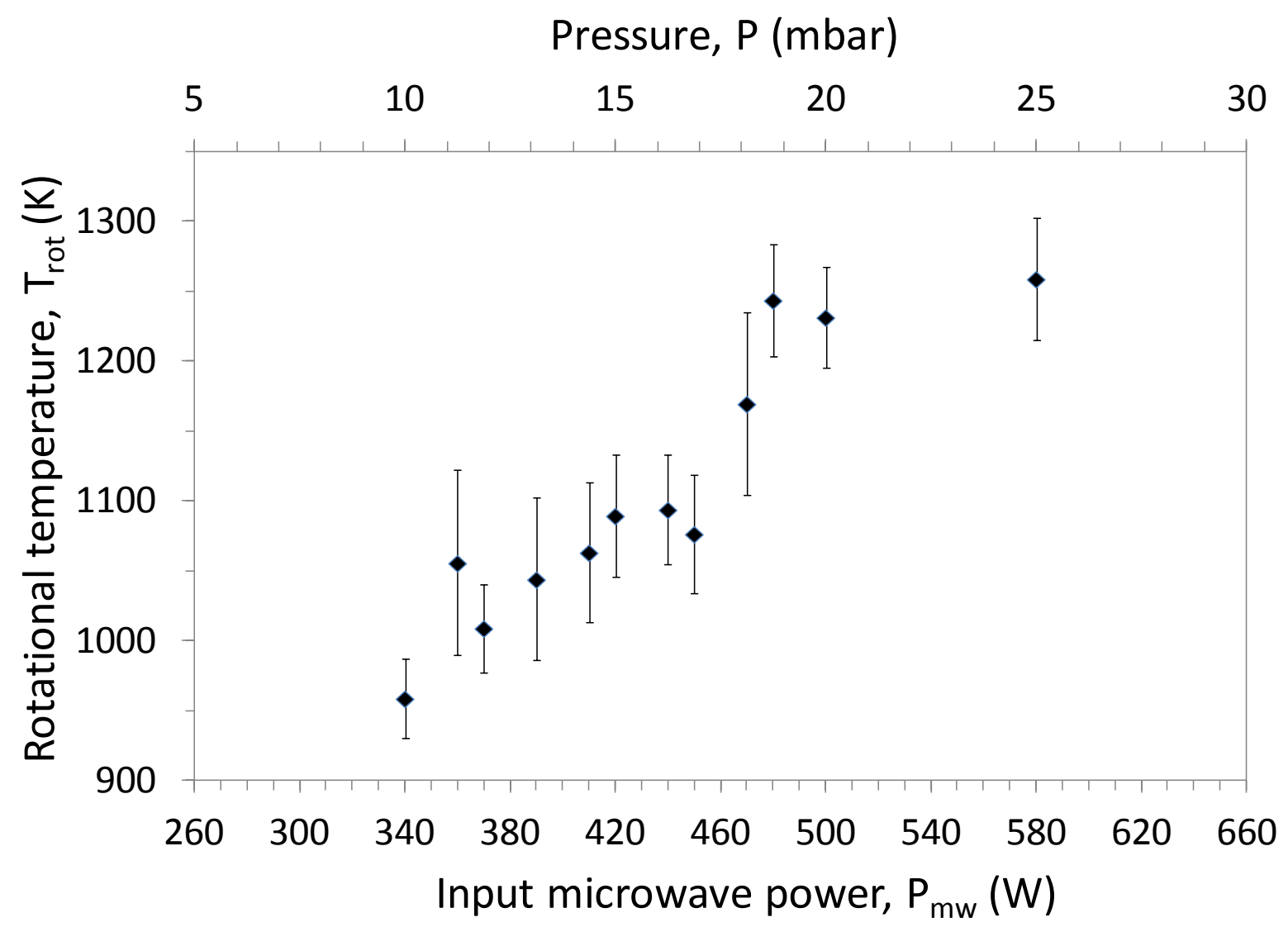

Figure 6. $\mathrm{H}_{2}$ rotational temperature measured by OES as a function of input microwave power.

When methane was added to the discharge, several atomic and molecular species were observed from the plasma in the visible spectrum, including $\mathrm{H}_{\alpha}, \mathrm{H}_{\beta}, \mathrm{H}_{\gamma}, \mathrm{H}_{2}, \mathrm{CH}$ and $\mathrm{C}_{2}$. In addition, $\mathrm{CN}$ lines arising from nitrogen impurities were observed; however, $\mathrm{CH}_{4}$ and $\mathrm{CH}_{3}$ cannot be detected via OES because they absorb rather than emit. The next set of measurements was conducted using a $\mathrm{CH}_{4} / \mathrm{H}_{2}$ reactant gas mixture. In this case, OES was used to qualitatively correlate plasma parameters with optimal graphene growth conditions based on a combination of process parameters explored in Ref. 76 to determine their effect on the graphene quality, as estimated using Raman spectroscopy [76]. In Table 3, we summarize the four optimal growth conditions issued from the Taguchi design based on two optimization criteria estimated from the relative Raman peak intensities, $\mathrm{I}_{2 \mathrm{D}} / \mathrm{I}_{\mathrm{G}}$, which are related to the number of layers; $\mathrm{I}_{\mathrm{D}} / \mathrm{I}_{\mathrm{G}}$ represents the density of the lattice defects in the graphene sample. In Table 3, OPT 1 and OPT 2 set parameters were obtained by considering only the individual influence of each chosen parameter without parameter interactions, whereas for OPT 3 and OPT 4, the conditions consider the interaction between the factors, providing better insight into the overall process analysis. 
Table 3. Set of parameters obtained for optimal Graphene growth as determined in Ref. 76.

\begin{tabular}{ccccccc}
\hline & \multicolumn{5}{c}{ Factor } \\
\cline { 2 - 7 } Exp. $\mathrm{N}^{\circ}$ a & $\begin{array}{c}\mathrm{Ts} \\
\left({ }^{\circ} \mathrm{C}\right)\end{array}$ & $\begin{array}{c}\Phi_{\mathrm{CH} 4} \\
(\mathrm{sccm})\end{array}$ & $\begin{array}{c}\Phi_{\mathrm{H} 2} \\
(\mathrm{sccm})\end{array}$ & $\begin{array}{c}\mathrm{t} \\
(\mathrm{sec})\end{array}$ & $\begin{array}{c}\mathrm{P} \\
(\mathrm{mbar})\end{array}$ & $\begin{array}{c}\mathrm{P}_{\mathrm{mw}} \\
(\mathrm{W})\end{array}$ \\
\hline OPT 1 & 700 & 1 & 50 & 30 & 13.8 & 400 \\
OPT 2 & 850 & 1 & 50 & 90 & 13.8 & 400 \\
OPT 3 & 870 & 1 & 50 & 90 & 13.8 & 400 \\
OPT 4 & 890 & 1 & 50 & 90 & 13.8 & 400 \\
\hline
\end{tabular}

${ }^{\mathrm{a}} \mathrm{T}_{\mathrm{s}}$ is the substrate temperature, $\Phi_{\mathrm{CH} 4}$ and $\Phi_{\mathrm{H} 2}$ are the methane and hydrogen flow rates respectively, $\mathrm{t}$ is the deposition time, $\mathrm{P}$ is the total gas pressure and $\mathrm{P}_{\mathrm{mw}}$ is the microwave power.

Rotational $\mathrm{H}_{2}$ temperatures measured at $1.7 \mathrm{~cm}$ above the substrate for the optimal graphene growth conditions shown in Figure 7.

From these results, we can conclude that the surface temperature and the introduction of $1 \mathrm{sccm}$ of methane in $50 \mathrm{sccm}$ hydrogen had no significant influence on the rotational temperature compared with $\mathrm{H}_{2}$ plasma at $400 \mathrm{~W}$.

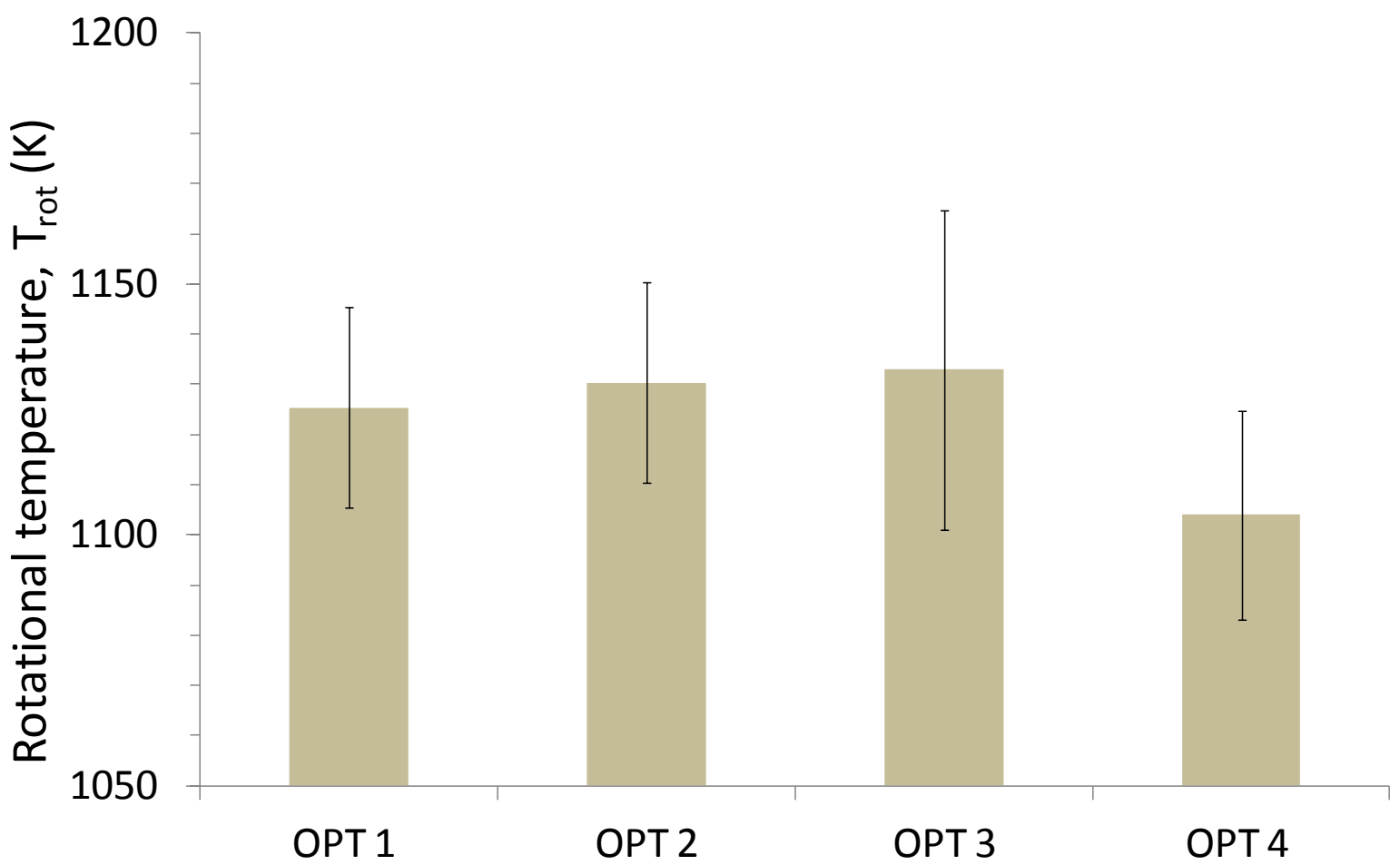


Figure 7. $\mathrm{H}_{2}$ rotational temperature measured by OES at the optimal graphene growth conditions of Table 3 .

When the substrate was changed from copper to cobalt under hydrogen plasma, no significant effect was observed on the $\mathrm{H}_{2}$ rotational temperature. Nevertheless, strong copper lines appear at $324.75 \mathrm{~nm}$ and $327.39 \mathrm{~nm}$ in Figure 8, indicating a possible partial evaporation of copper and/or hydrogen plasma etching of copper. This result is attributed to the highest substrate temperature used for copper, $980^{\circ} \mathrm{C}$, compared to the $700^{\circ} \mathrm{C} \leq \mathrm{Ts} \leq$ $890^{\circ} \mathrm{C}$ used for cobalt.

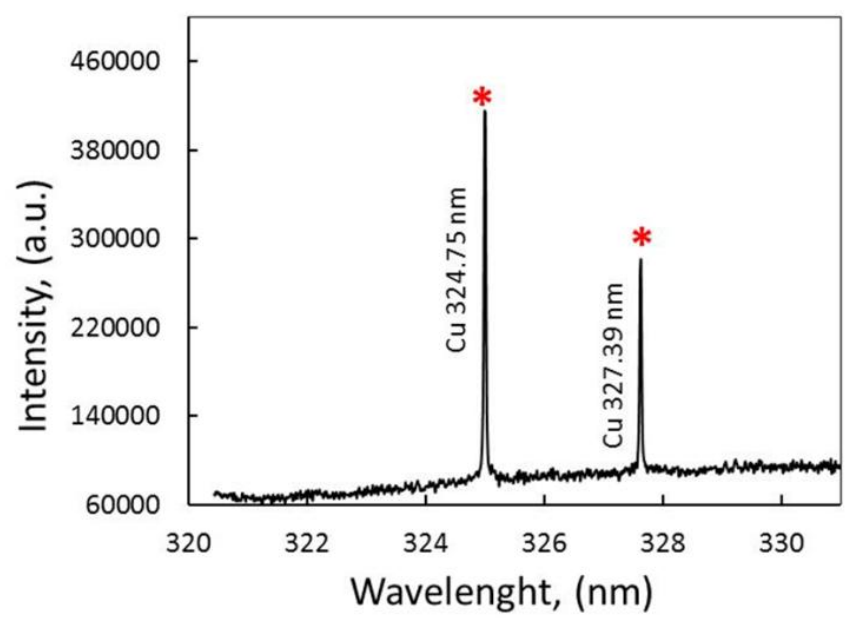

Figure 8. Copper lines observed from emission spectrum in pure hydrogen when copper catalyst is used.

Microwave power $=390 \mathrm{~W}$, pressure $=13 \mathrm{mbar}$ and substrate temperature $=980{ }^{\circ} \mathrm{C}$. The stars refers to the copper lines as obtained from emission spectrum of neutral and ionized copper plasma in Ref.105.

Notably, the estimation of the excitation rate constants requires knowledge of the electron temperature, which in our case was estimated from the $0 \mathrm{D}$ and 2D models as described in section III. To determine the rotational temperature, we separated the OES measurements of the H- $\alpha$ and Ar lines into two different sets of experiments: one in the presence of pure hydrogen only, and the second for a mixture of $\mathrm{H}_{2}$ and $\mathrm{CH}_{4}$. For pure $\mathrm{H}_{2}$, the values of the pressure and microwave power were varied simultaneously as in the previously discussed determination of the rotational temperature. The pressure and power were varied from 10 to 20 mbar and from 340 to $500 \mathrm{~W}$. The substrate temperature was set to $870^{\circ} \mathrm{C}$ and the flow rate of $\mathrm{H}_{2}$ and $\mathrm{Ar}$ were $50 \mathrm{sccm}$ and $3 \mathrm{sccm}$, respectively. In the second set of measurements, the conditions for graphene synthesis shown in Table 3 were used as process 
parameters. Figure 10 represents the established values of the mole fraction of atomic hydrogen measured under the optimal conditions.

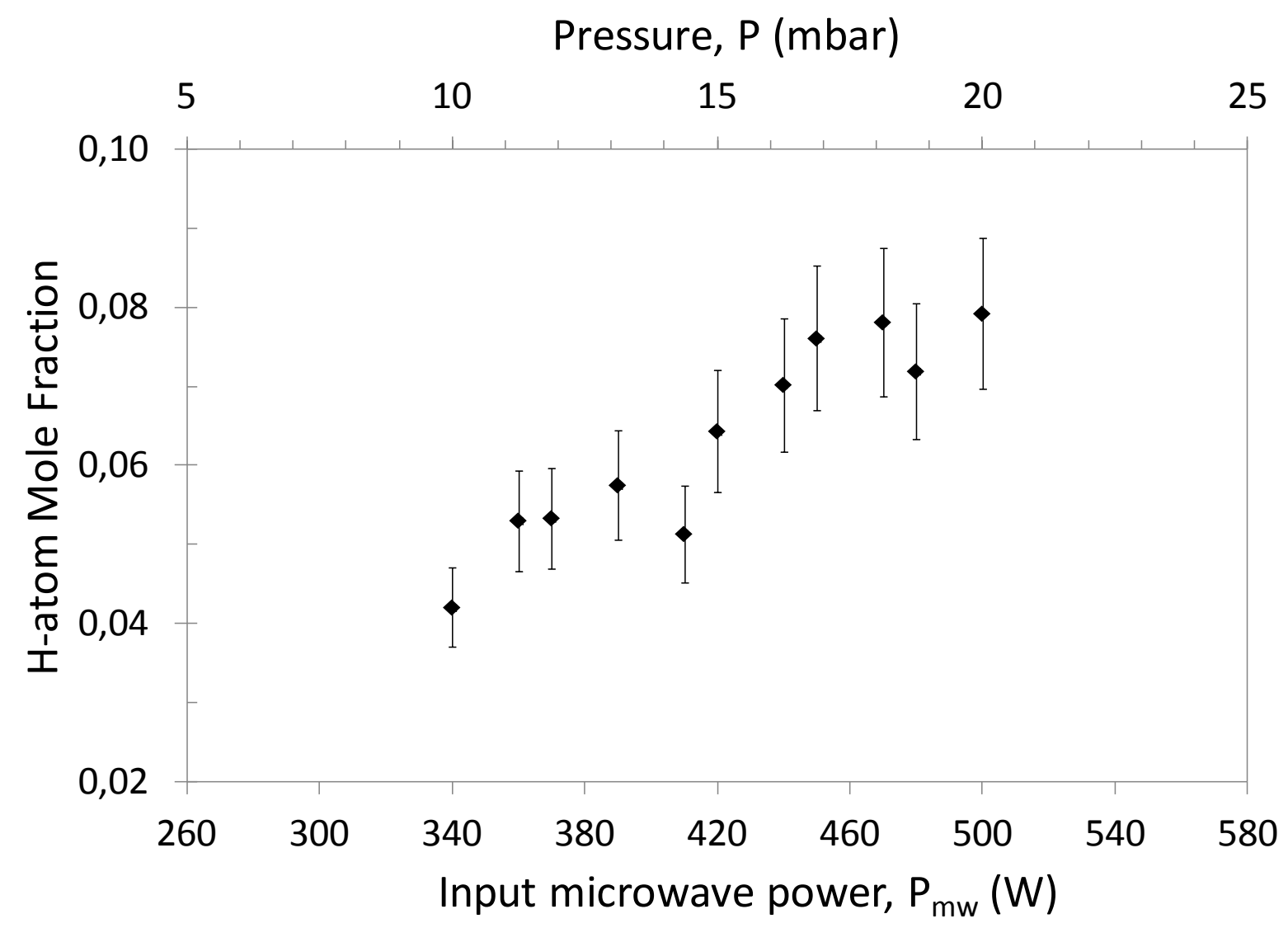

Figure 9. Atomic hydrogen mole fraction determined from actinometry as a function of input microwave power.

In Figure 9, increasing the microwave power from $340 \mathrm{~W}$ to $500 \mathrm{~W}$ clearly increases the $\mathrm{H}$ atom mole fraction from $\sim 4 \%$ mol. to $\sim 8 \%$ mol. This result is attributed to the improvement of the thermal dissociation of molecular hydrogen due to the increase in the gas temperature, as already shown in Figure 6. Increasing the gas temperature also increases the collision frequency, making the dissociation by collision with electrons more effective. 


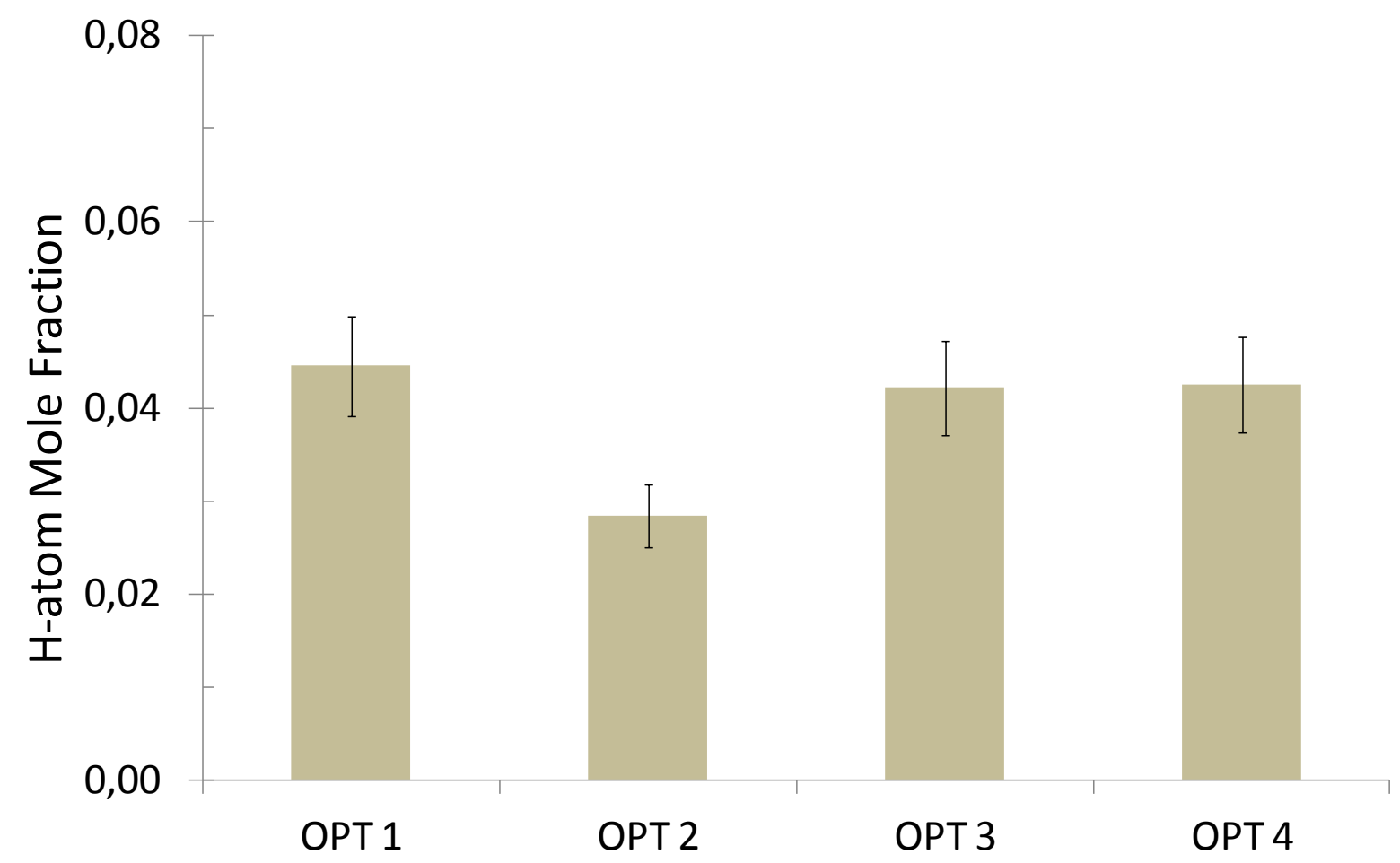

Figure 10. Atomic hydrogen mole fraction as determined from actinometry in the optimal graphene growth conditions of Table 3 .

From Figure 10, we can see a fairly constant atomic hydrogen concentration in the center of the plasma. Since the only parameter varied is the substrate temperature, we conclude that this factor weakly affects the plasma parameters.

\section{B. Modeling results}

To illustrate the 0D model, the optimal growth conditions OPT 1 to OPT 4 were solved. Time evolution of the solution was used for sensitivity analysis of the reaction network. A typical time evolution of the solution is provided in Figure 11 for OPT 1 conditions. By considering the previously discussed detailed kinetics, we can see that gas-phase decomposition of $\mathrm{CH}_{4}$ produces numerous hydrocarbons. Under these conditions, most of the methane introduced into the reactor is transformed to acetylene in a few milliseconds. 


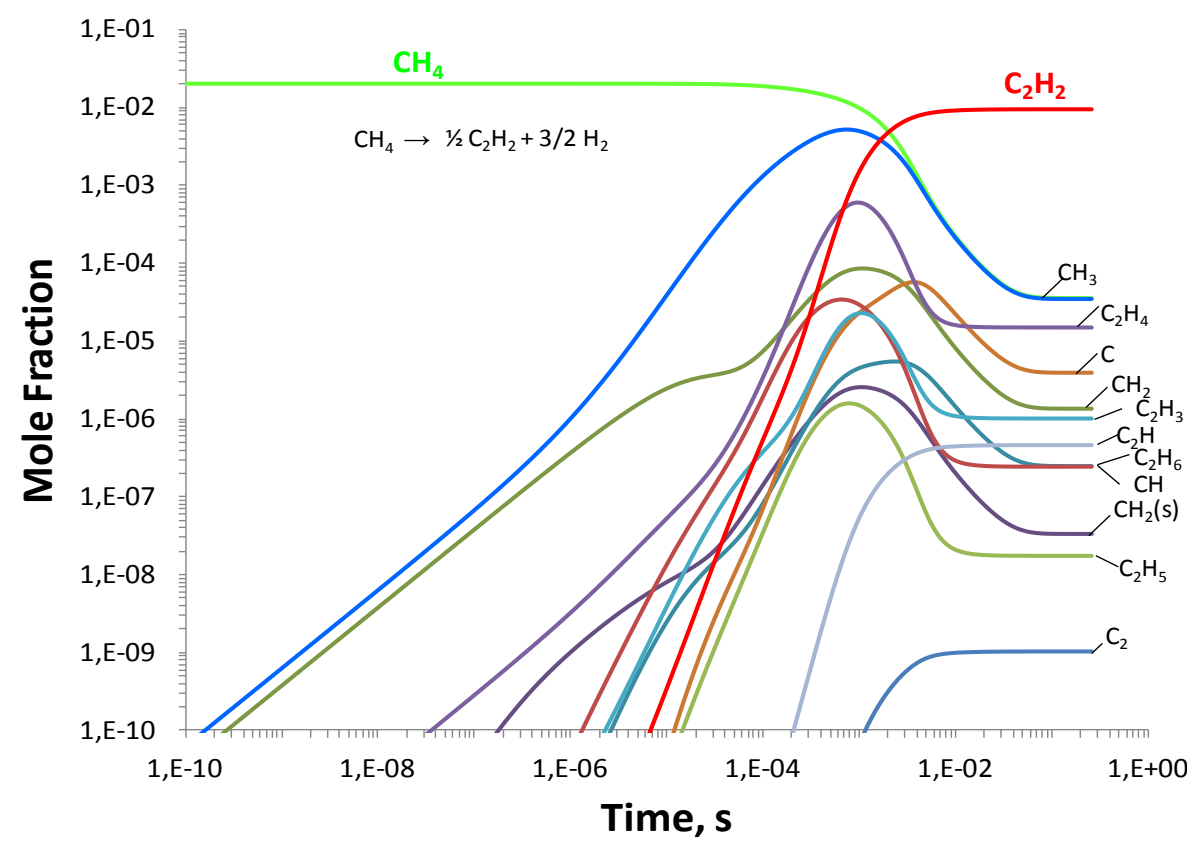

Figure 11. Time evolution of small $\mathrm{C}_{1}-\mathrm{C}_{2}$ carbon species mole fractions calculated from Table 3, OPT 1 conditions. Global reaction transforming input methane to acetylene. $\mathrm{Ts}=700^{\circ} \mathrm{C}, \mathrm{P}=13 \mathrm{mbar}, \Phi_{\mathrm{CH} 4}=1 \mathrm{sccm}$, $\Phi_{\mathrm{H} 2}=50 \mathrm{sccm}$ and $\mathrm{P}_{\mathrm{mw}}=400 \mathrm{~W}$.

From Figure 12, which shows the major species in the plasma, we conclude that the discharge is dominated by atomic hydrogen, which is the second species after molecular hydrogen which is the second species after the molecular hydrogen.

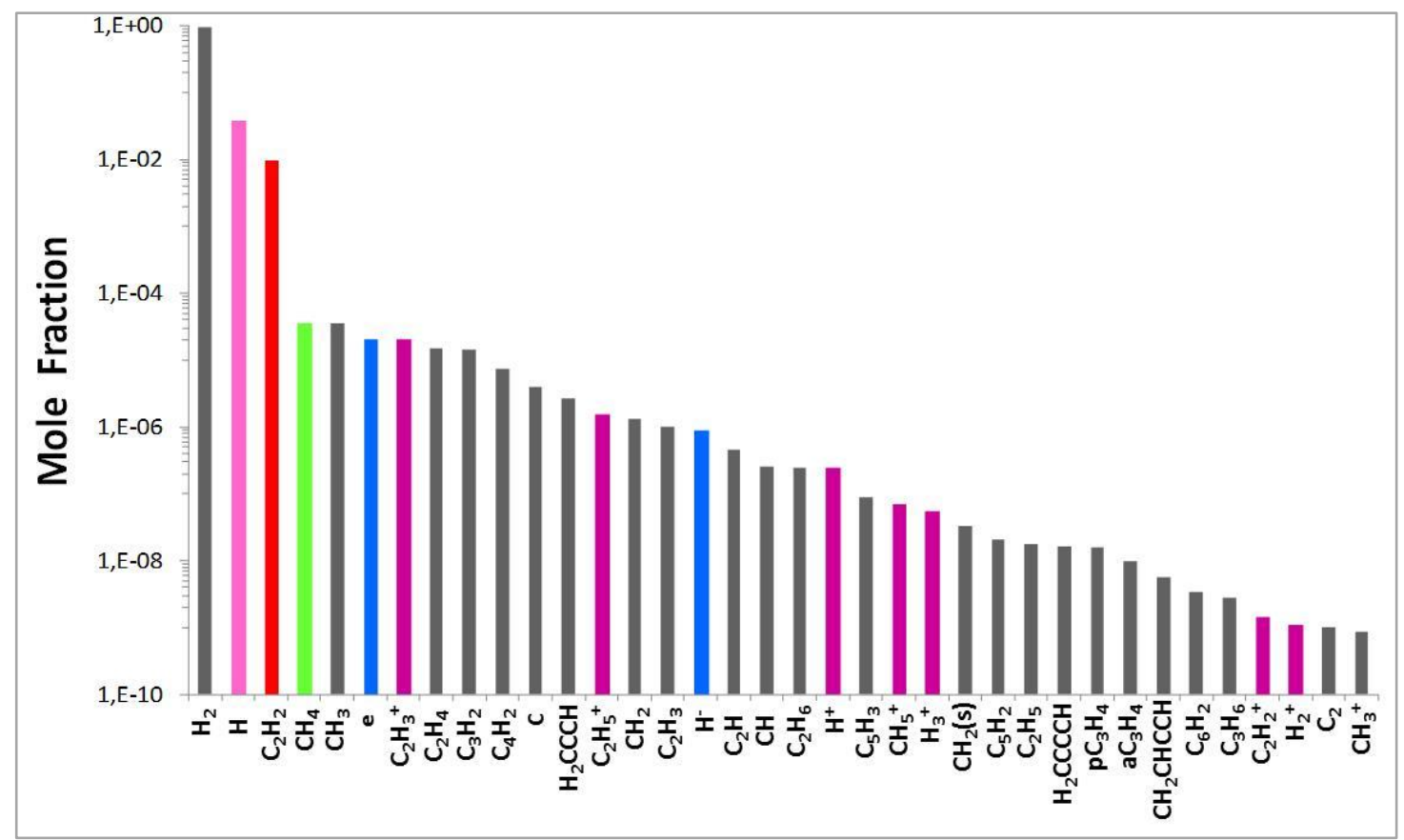


Figure 12. Major species calculated from Table 3 , OPT 1 conditions. $\mathrm{Ts}=700^{\circ} \mathrm{C}, \mathrm{P}=13 \mathrm{mbar}, \Phi_{\mathrm{CH} 4}=1 \mathrm{sccm}$, $\Phi_{\mathrm{H} 2}=50 \mathrm{sccm}$ and $\mathrm{P}_{\mathrm{mw}}=400 \mathrm{~W}$.

The calculated $\mathrm{H}$-atom mole fraction $\mathrm{x}_{\mathrm{H}}=0.038$ in the center of the plasma is in good agreement with the OES measurements $\left(\mathrm{x}_{\mathrm{H}, \mathrm{OES}}=0.045\right)$. Indeed, microwave plasma is known to improve hydrogen dissociation via electronic processes. Acetylene is the first carbon species, and it is produced via fast processes $\mathrm{C}_{2} \mathrm{H}_{3}+\mathrm{H} \rightarrow \mathrm{C}_{2} \mathrm{H}_{2}$ $+\mathrm{H}_{2}$ and $\mathrm{C}_{2} \mathrm{H}_{4}+\mathrm{M} \rightarrow \mathrm{C}_{2} \mathrm{H}_{2}+\mathrm{H}_{2}+\mathrm{M}$ and is consumed primarily by ion-neutral reactions $\mathrm{H}_{3}^{+}+\mathrm{C}_{2} \mathrm{H}_{2} \rightarrow \mathrm{C}_{2} \mathrm{H}_{3}{ }^{+}+$ $\mathrm{H}_{2}$.

From Figure 11 and by analyzing the rates of the forward and reverse reactions, we find that the forward reaction (R1) $\mathrm{H}+\mathrm{CH}_{4} \leftrightarrow \mathrm{CH}_{3}+\mathrm{H}_{2}$ is the most important initial step in the formation of $\mathrm{CH}_{3}$, whereas the rate of the reaction e- $+\mathrm{CH}_{4} \rightarrow$ e- $+\mathrm{CH}_{3}+\mathrm{H}$ is approximately 100 times lower. The dominant reaction of destruction of methyl is (R2) $\mathrm{H}+\mathrm{CH}_{3}+\mathrm{M} \rightarrow \mathrm{CH}_{4}+\mathrm{M}$ followed by $2 \mathrm{CH}_{3} \rightarrow \mathrm{C}_{2} \mathrm{H}_{4}+\mathrm{H}_{2}$. Atomic hydrogen is produced by (R3) e- $+\mathrm{H}_{2} \rightarrow \mathrm{H}+\mathrm{H}+$ e-, which is controlled by the electronic temperature, followed by (R4) $2 \mathrm{H}_{2} \rightarrow 2 \mathrm{H}+\mathrm{H}_{2}$, which is controlled by the gas temperature. The rate of (R4) is 2 times lower than that of (R3). The peak of the $\mathrm{CH}_{3}$ mole fraction in Figure 11 clearly illustrates the critical effect of atomic hydrogen on improving methyl production until $\sim 6 \times 10^{-4} \mathrm{~s}$ and on improving its destruction after this time. The surface concentration calculated from Eq. (29) gives a relatively high atomic hydrogen concentration, $[\mathrm{H}]_{\text {surf }}=1.1 \times 10^{-9}$ mol.cm ${ }^{-3}$; however, $\left[\mathrm{CH}_{3}\right]_{\text {surf }}=4.5 \times 10^{-12} \mathrm{~mol} . \mathrm{cm}^{-3}$ is approximately three orders of magnitude lower. In contrast to CVD diamond, graphene is not thought to grow from $\mathrm{CH}_{3}$ radicals. Figure 13 shows the time variation of ions and electrons. Figures 12 and 13 show that the major cation in the plasma is $\mathrm{C}_{2} \mathrm{H}_{3}{ }^{+}$and not $\mathrm{H}_{3}{ }^{+}$as in pure hydrogen plasma; this effect is attributed to the reaction $\mathrm{H}_{3}^{+}+\mathrm{C}_{2} \mathrm{H}_{2} \rightarrow \mathrm{C}_{2} \mathrm{H}_{3}{ }^{+}+\mathrm{H}_{2}$. In the absence of $\mathrm{H}_{3}{ }^{+}$, the production of the reaction $\mathrm{H}_{3}{ }^{+}+\mathrm{H}^{-} \rightarrow 2 \mathrm{H}_{2}$ become negligible, which explains the relatively large amount of $\mathrm{H}^{-}$. 


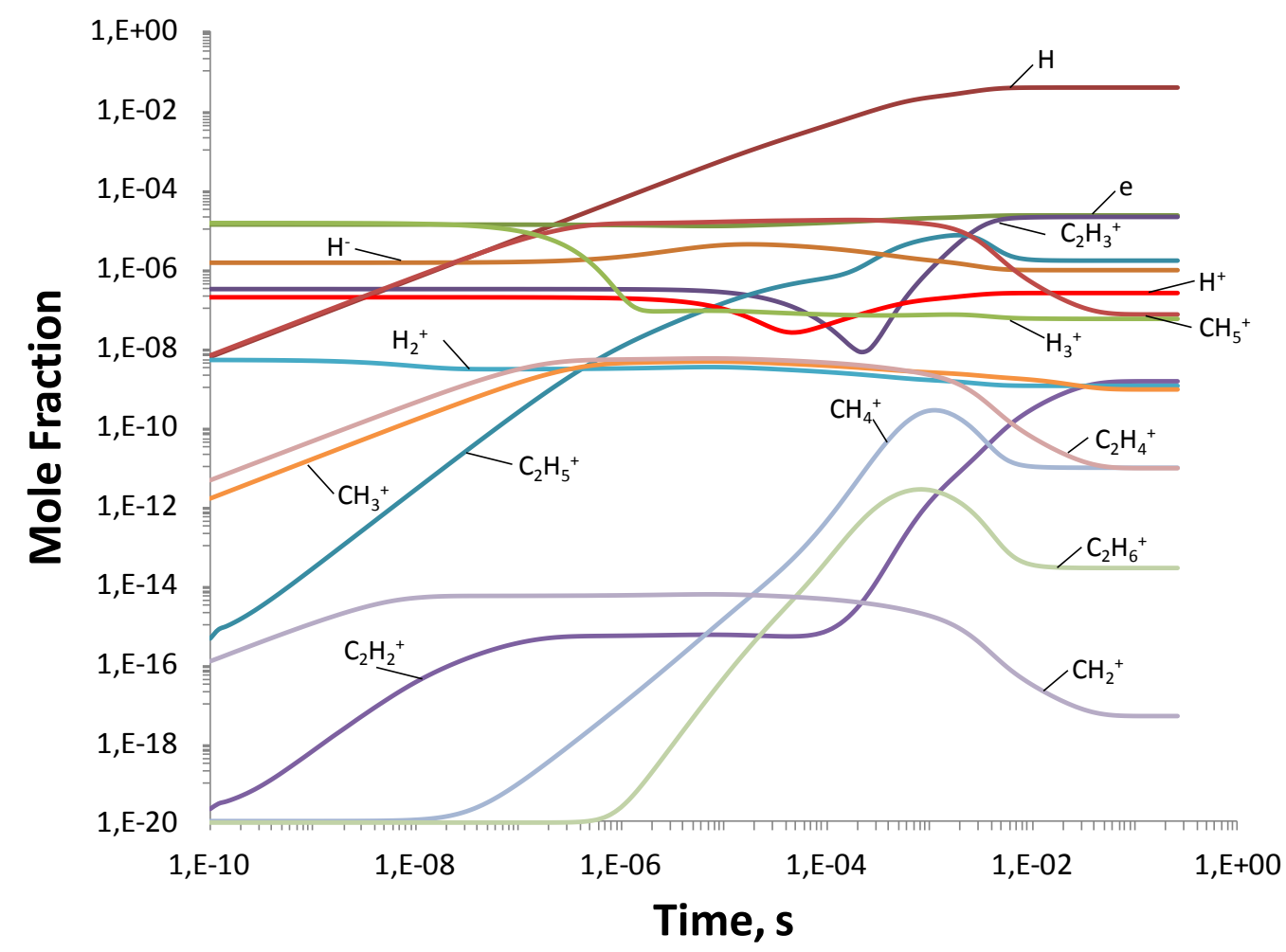

Figure 13. Time evolution of $\mathrm{H}$ atoms, electrons and positive and negative ions mole fractions calculated from Table 3, OPT 1 conditions. The species are classified in their order of abundance in the legend. Ts $=700^{\circ} \mathrm{C}, \mathrm{P}=13$ mbar, $\Phi_{\mathrm{CH} 4}=1 \mathrm{sccm}, \Phi_{\mathrm{H} 2}=50 \mathrm{sccm}$ and $\mathrm{P}_{\mathrm{mw}}=400 \mathrm{~W}$.

In addition, hydrogen molecules in highly vibrationally excited states can enhance the production of anions, primarily through dissociative attachment of hydrogen molecules. Major charged species follow the order $\mathrm{e}^{-}>\mathrm{C}_{2} \mathrm{H}_{3}{ }^{+}>\mathrm{C}_{2} \mathrm{H}_{5}{ }^{+}>\mathrm{H}^{-}>\mathrm{H}^{+}>\mathrm{CH}_{5}{ }^{+}>\mathrm{H}_{3}{ }^{+}$. Figure 14 shows the mole fraction of the most important polycyclic aromatic hydrocarbons (PAHs) in the plasma. If these PAHs are present in a very small mole fraction $\mathrm{x}_{\mathrm{PAH}}<10^{-10}$, they are thought to nucleate soot particles [106] and could also play a role in graphene nucleation. 


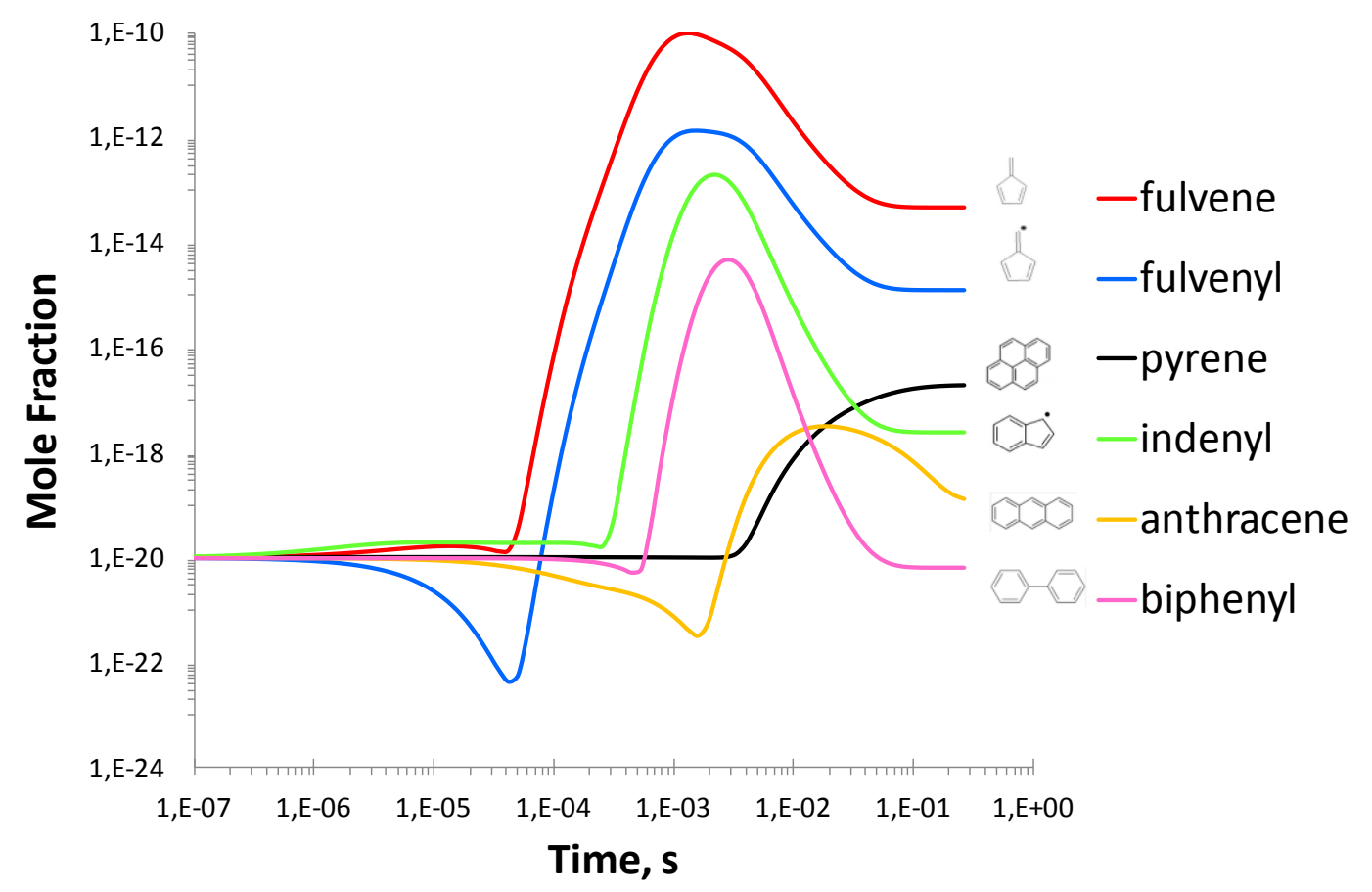

Figure 14. Time evolution of polycyclic aromatic hydrocarbons (PAHs) carbon species calculated from Table 3, OPT 1 conditions. Ts $=700^{\circ} \mathrm{C}, \mathrm{P}=13 \mathrm{mbar}, \Phi_{\mathrm{CH} 4}=1 \mathrm{sccm}, \Phi_{\mathrm{H} 2}=50 \mathrm{sccm}$ and $\mathrm{P}_{\mathrm{mw}}=400 \mathrm{~W}$.

As shown in Figure 15, the calculated electron temperature is $15,870 \mathrm{~K}(1.38 \mathrm{eV})$, in agreement with the calculations of Ma et al., who estimated $1.26<\mathrm{Te}<1.32 \mathrm{eV}$ in $\mathrm{CH}_{4} \mathrm{Ar} / \mathrm{H}_{2}$ plasma operating under similar conditions [91]. The gas temperature calculated by our 0D model gives $\mathrm{T}=1608 \mathrm{~K}$, which exceeds the measured rotational temperature $(1145 \mathrm{~K})$, suggesting that the $\mathrm{H}_{2}$ rotational temperature may underestimate the gas temperature. The same conclusion was proposed by Lang et al. [85], who compared the gas temperature estimated from the $\mathrm{H}_{2}$ rotational temperature with that obtained from Doppler broadening of the $\mathrm{H}_{\alpha}$ line. From the calculated $\mathrm{Tv} \sim 2228 \mathrm{~K}$ reported in Figure 15 , we conclude that a vibrational disequilibrium of $\sim 620 \mathrm{~K}$ is present in our plasma. This disequilibrium contributes to anion formation by dissociative attachment, which is known to depend on the vibrational excitation. Increasing the plasma power increases simultaneously $\mathrm{T}$ and $\mathrm{TV}$ but decreases the vibrational disequilibrium. Figure 15 also provides the details of the power deposition obtained at the steady-state converged solution. The power absorbed from the microwaves by the electrons $\mathrm{P}_{\mathrm{abs}}$ is transferred to the neutral gas during collisions primarily through the $\mathrm{Q}_{\mathrm{ev}}$ channel, followed by $\mathrm{Q}_{\mathrm{ed}}$ and $\mathrm{Q}_{\mathrm{et}}$ as described in Eq. (S3-S6) in supplementary material. 


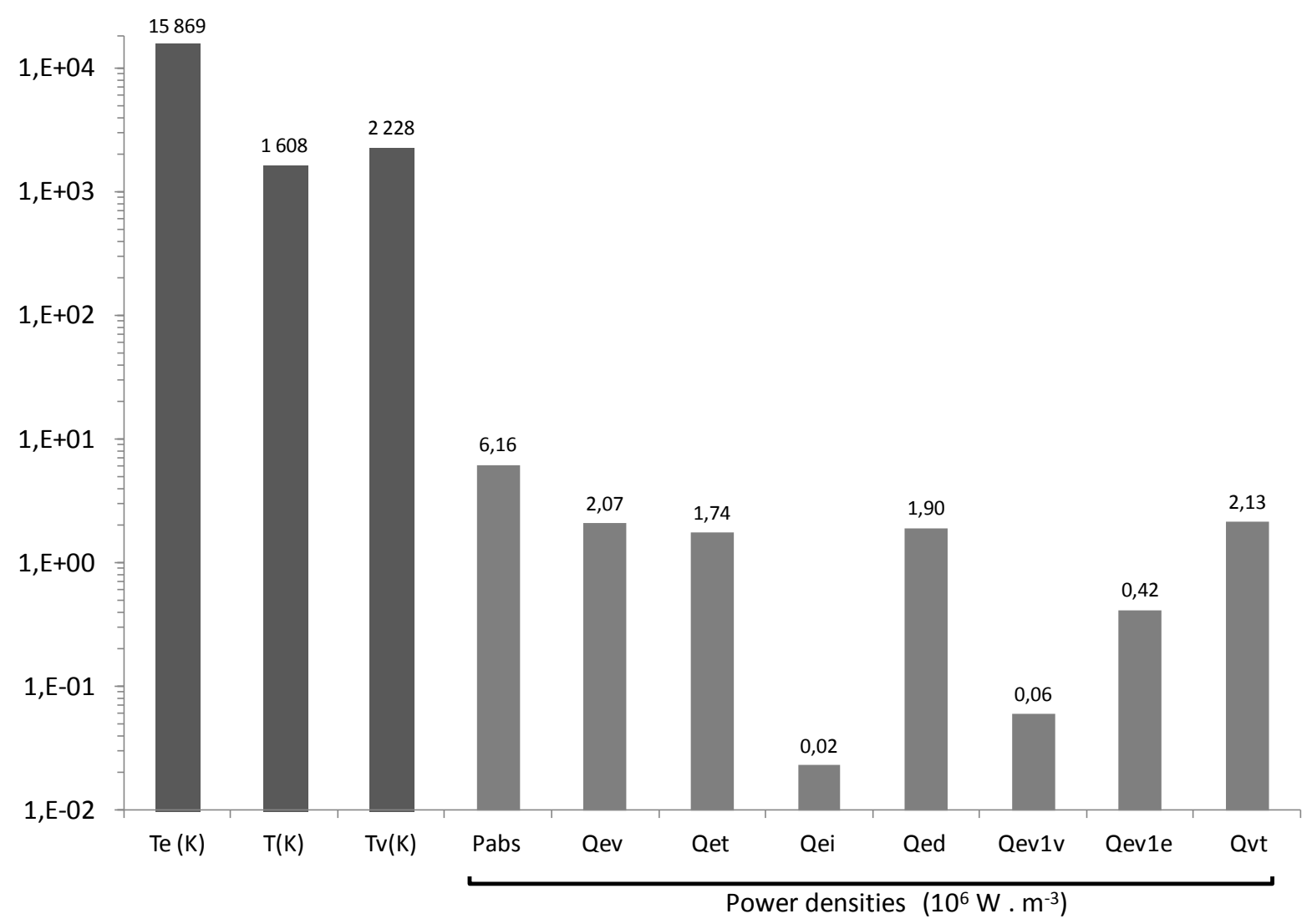

Figure 15. Electron, gas and vibration temperatures, absorbed power and electron and vibration energy exchange calculated for OPT 1 conditions. Ts $=700^{\circ} \mathrm{C}, \mathrm{P}=13 \mathrm{mbar}, \Phi_{\mathrm{CH} 4}=1 \mathrm{sccm}, \Phi_{\mathrm{H} 2}=50 \mathrm{sccm}$ and $\mathrm{P}_{\mathrm{mw}}=400 \mathrm{~W}$.

The 2D model was solved for the OPT 3 growth conditions given in Table 3. Figure 16 shows the contours of the electron and gas temperatures. The maximum gas temperature is located at a $\delta_{\mathrm{T}}$ of $1.6 \mathrm{~cm}$ above the substrate. This validates the boundary-layer thickness used in the OD model $(\delta=1.7 \mathrm{~cm})$. The results of the 2D self-consistent model compare well with experiments and with the OD model with respect to the gas and electron temperatures. This result indicates that the mechanisms of energy transfer from electrons to heavy species have been well captured in both models. The electron temperature profile has two foci: the first is closer to the substrate, and the second is shifted from the thermal boundary $\delta_{\mathrm{T}}$. The electron temperature at the center of the plasma is approximately $17,500 \mathrm{~K}(1.5 \mathrm{eV})$. The electron number density values shown in Figure 17-a remain fairly uniform in the axial and radial plasma directions. The electron mole fraction in the plasma is found to be $2 \times 10^{-6}$, which is an order of magnitude lower than that of the OD simulations. This result is likely attributable to the diffusion of electrons, which is neglected in the OD model but is apparent from the presence of relatively significant electron concentrations outside the plasma region. Figure 17-b shows the self-consistently calculated power density distribution in the reactor. The maximum of the power density is located close to the 
substrate and is approximately $2 \times 10^{6} \mathrm{~W} \cdot \mathrm{m}^{-3}$ (zone A in Figure 17-b), which corresponds to the normal operating conditions. We can also distinguish a secondary antinode located close to the top of the quartz reactor with a still-weak power density of $\sim 8 \times 10^{4} \mathrm{~W} . \mathrm{m}^{-3}$ (zone B in Figure 17-b), which primarily arises from the presence of a significant amount electrons in the colder regions of the plasma, as explained earlier. Consequently, the fraction of MW energy dissipated inside the plasma region is approximately 0.25 -fold the total MW power injected into the reactor. This again partly explains the lower concentrations of electrons compared to that of the 0D simulations. As observed experimentally and numerically, increasing the plasma power at constant pressure increases the power density in zone B, thereby creating a secondary plasma ball [103]. This leads to an unstable plasma, which is not desirable for graphene growth.
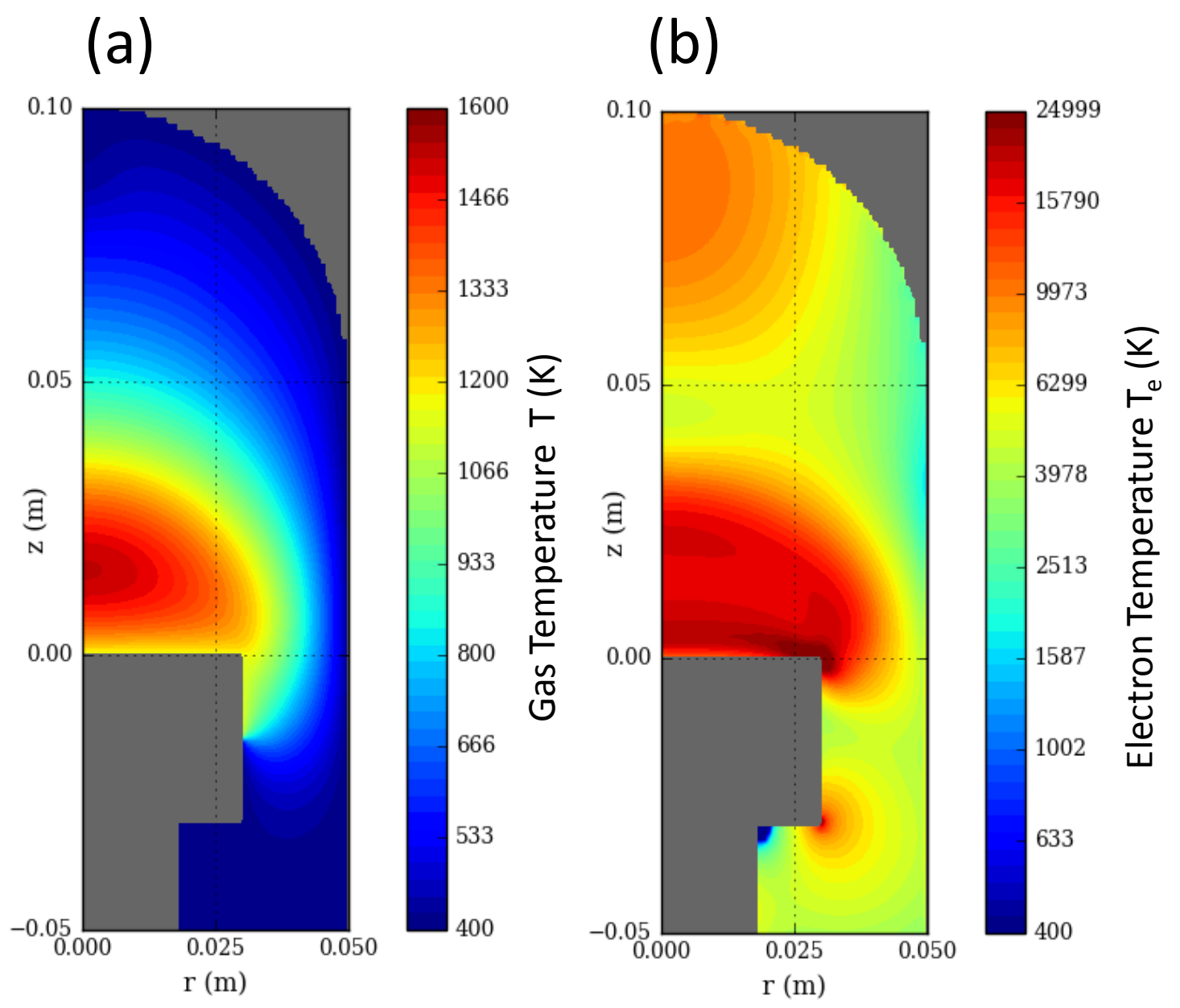

Figure 16. Contours of (a) gas temperature $\mathrm{T}$ and (b) electron temperature $\mathrm{T}_{\mathrm{e}}$ calculated from Table 3 , OPT 3 conditions. $\mathrm{z}$ and $\mathrm{r}$ are axial and radial position in meters, respectivel $\mathrm{Ts}=870^{\circ} \mathrm{C}, \mathrm{P}=13 \mathrm{mbar}, \Phi_{\mathrm{CH} 4}=1 \mathrm{sccm}, \Phi_{\mathrm{H} 2}=50 \mathrm{sccm}$ and $\mathrm{P}_{\mathrm{mw}}=400 \mathrm{~W}$. 
(a)

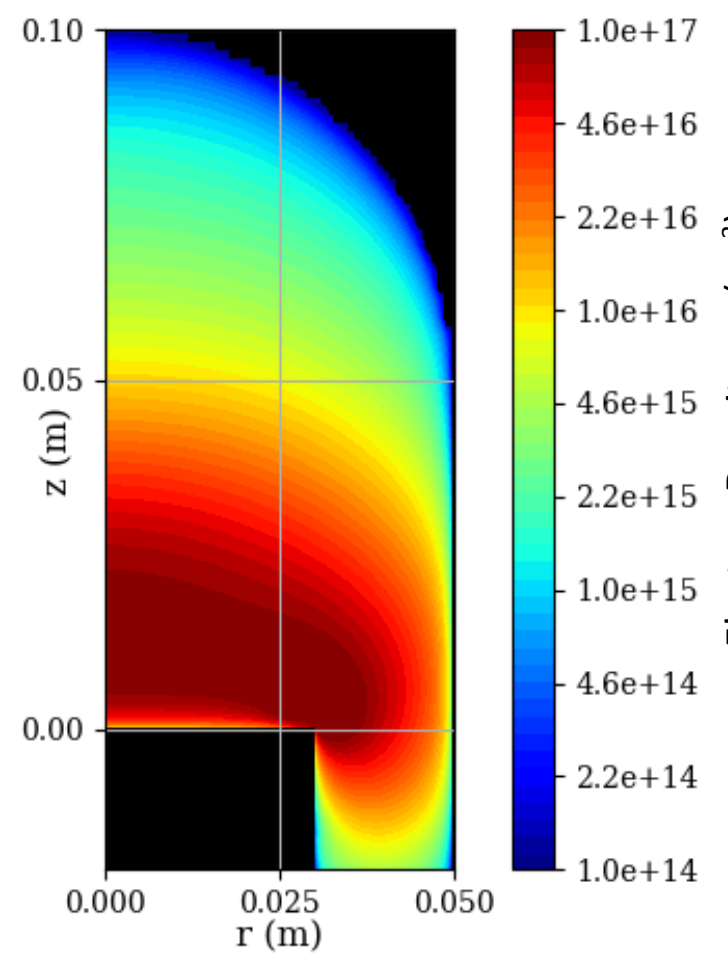

(b)

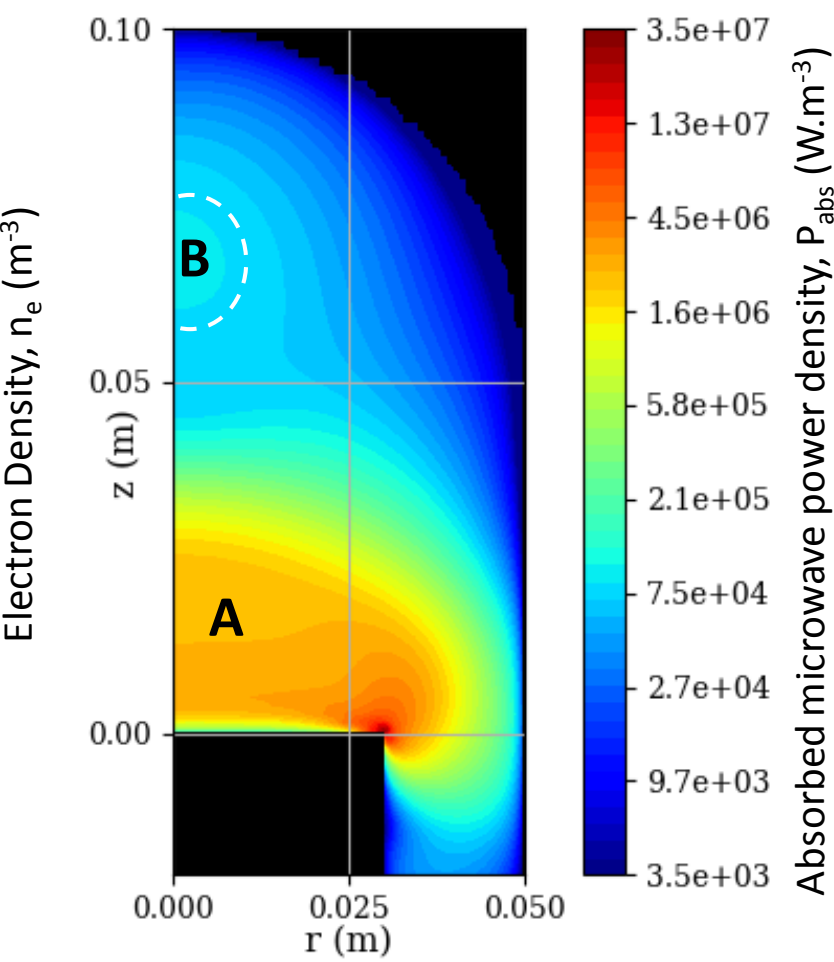

Figure 17. (a) Electron density and (b) absorbed power density contours. Calculated from Table 3, OPT 3 conditions. $\mathrm{z}$ and $\mathrm{r}$ are axial and radial position in meters, respectively. Ts $=870^{\circ} \mathrm{C}, \mathrm{P}=13 \mathrm{mbar}, \Phi_{\mathrm{CH} 4}=1 \mathrm{sccm}$, $\Phi_{\mathrm{H} 2}=50 \mathrm{sccm}$ and $\mathrm{P}_{\mathrm{mw}}=400 \mathrm{~W}$.

Figure 18 shows a plot the contours of some of the major species in the reactor under OPT 3 conditions. Atomic hydrogen $\mathrm{H}, \mathrm{CH}_{3}$ and $\mathrm{C}$ are located primarily in the plasma region whereas the methane concentration is higher in the zone between the plasma ball and the reactor wall. However, contrary to the $0 \mathrm{D}$ model, the major carbon species in the plasma region is methane and the acetylene concentration is quite low (mole fraction of $5 \times 10^{-4}$ ), likely due to the diffusion of methane from colder regions of the reactor under such low-pressure conditions, which is not considered in the $0 \mathrm{D}$ model. The acetylene concentration reaches a maximum at the substrate surface, and it likely contributes to graphene growth. In addition, the major ionic species from this simulation is $\mathrm{C}_{2} \mathrm{H}_{5}{ }^{+}$, in contrast to $\mathrm{C}_{2} \mathrm{H}_{3}{ }^{+}$in the $0 \mathrm{D}$ simulation. The presence of methane in the plasma zone can alter the prevailing nonequilibrium conditions and thus alter the species composition. As observed, the presence of methane also increased the concentration of the $\mathrm{CH}_{3}$ radical to a mole fraction of approximately $10^{-3}$, compared with $3 \times 10^{-5}$ obtained from the $0 \mathrm{D}$ model; the $\mathrm{CH}_{3}$ radical may play an important role in the growth of graphene. Moreover, the $\mathrm{H}$ concentration was found to be less than $1 \%$, which is much lower than what was obtained from the experiments and the $0 \mathrm{D}$ model. This result is attributable to the lower electron concentrations predicted by 
the self-consistent model, as one of the important pathways for the formation of atomic hydrogen is through electron-impact dissociation of molecular hydrogen. Otherwise, this result is attributable to the reduced chemistry scheme used in the auto-coherent model and the possible absence of important species such as $\mathrm{H}^{-}$ions. As evident from the OD simulations, the absence of $\mathrm{H}^{3+}$ ions should increase the concentration of $\mathrm{H}^{-}$and cannot be neglected under such low-pressure conditions.

To improve the accuracy of the models, transport in the OD simulation should be accounted for and the reduced chemistry scheme for the $2 \mathrm{D}$ should be improved. However, despite the differences between the models, the plasma conditions are qualitatively accurate.
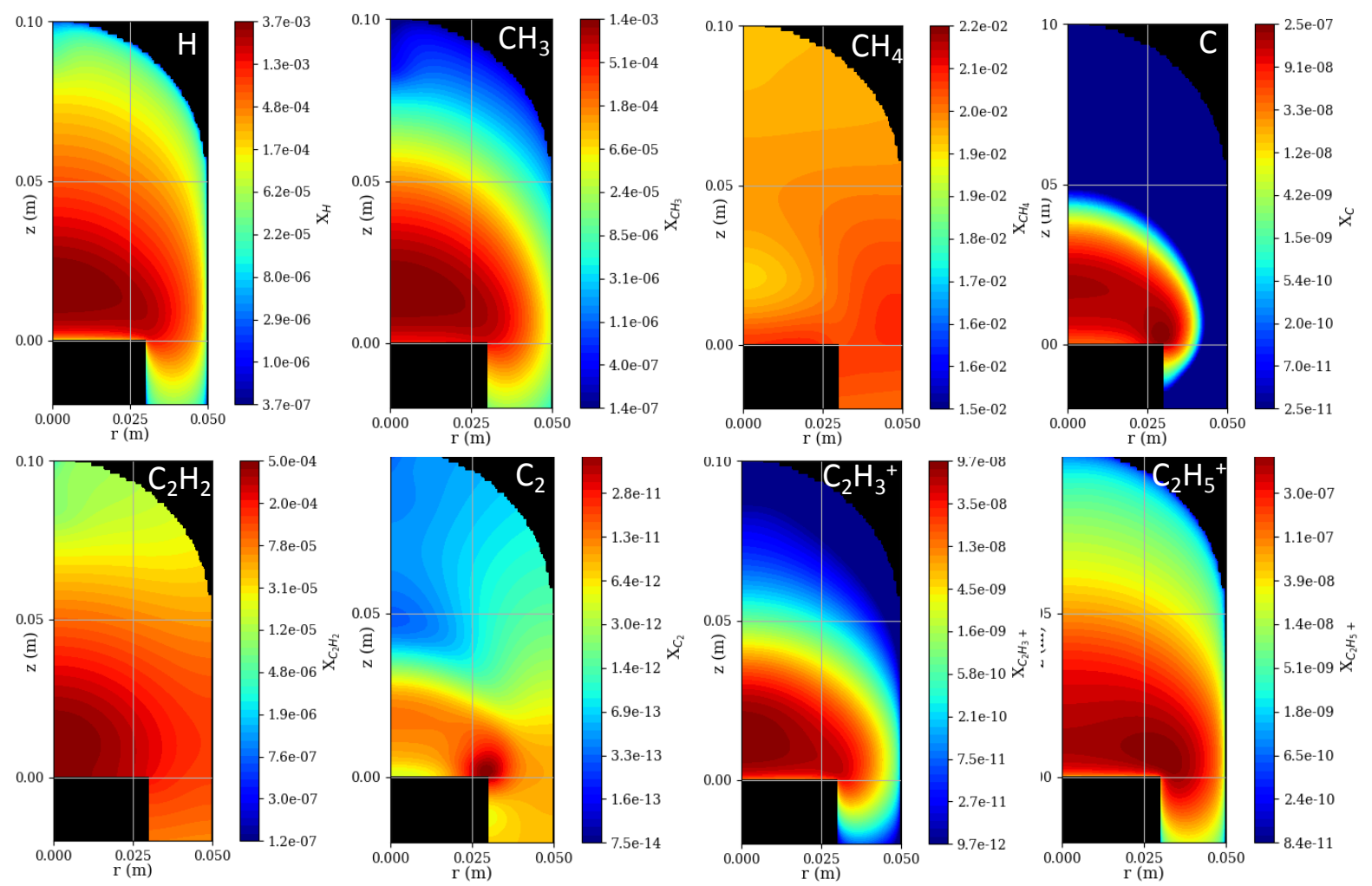

Figure 18. Specie mole fraction contours for $\mathrm{H}, \mathrm{CH}_{3}, \mathrm{CH}_{4}, \mathrm{C}$ (Top from left to right) and $\mathrm{C}_{2} \mathrm{H}_{2}, \mathrm{C}_{2}, \mathrm{C}_{2} \mathrm{H}_{3}{ }^{+}$and $\mathrm{C}_{2} \mathrm{H}_{5}{ }^{+}$(Bottom from left to right) calculated from Table 3, OPT 3 conditions. $\mathrm{z}$ and $\mathrm{r}$ are axial and radial position in meters, respectively. $\mathrm{Ts}=870^{\circ} \mathrm{C}, \mathrm{P}=13 \mathrm{mbar}, \Phi_{\mathrm{CH} 4}=1 \mathrm{sccm}, \Phi_{\mathrm{H} 2}=50 \mathrm{sccm}$ and $\mathrm{P}_{\mathrm{mw}}=400 \mathrm{~W}$. 


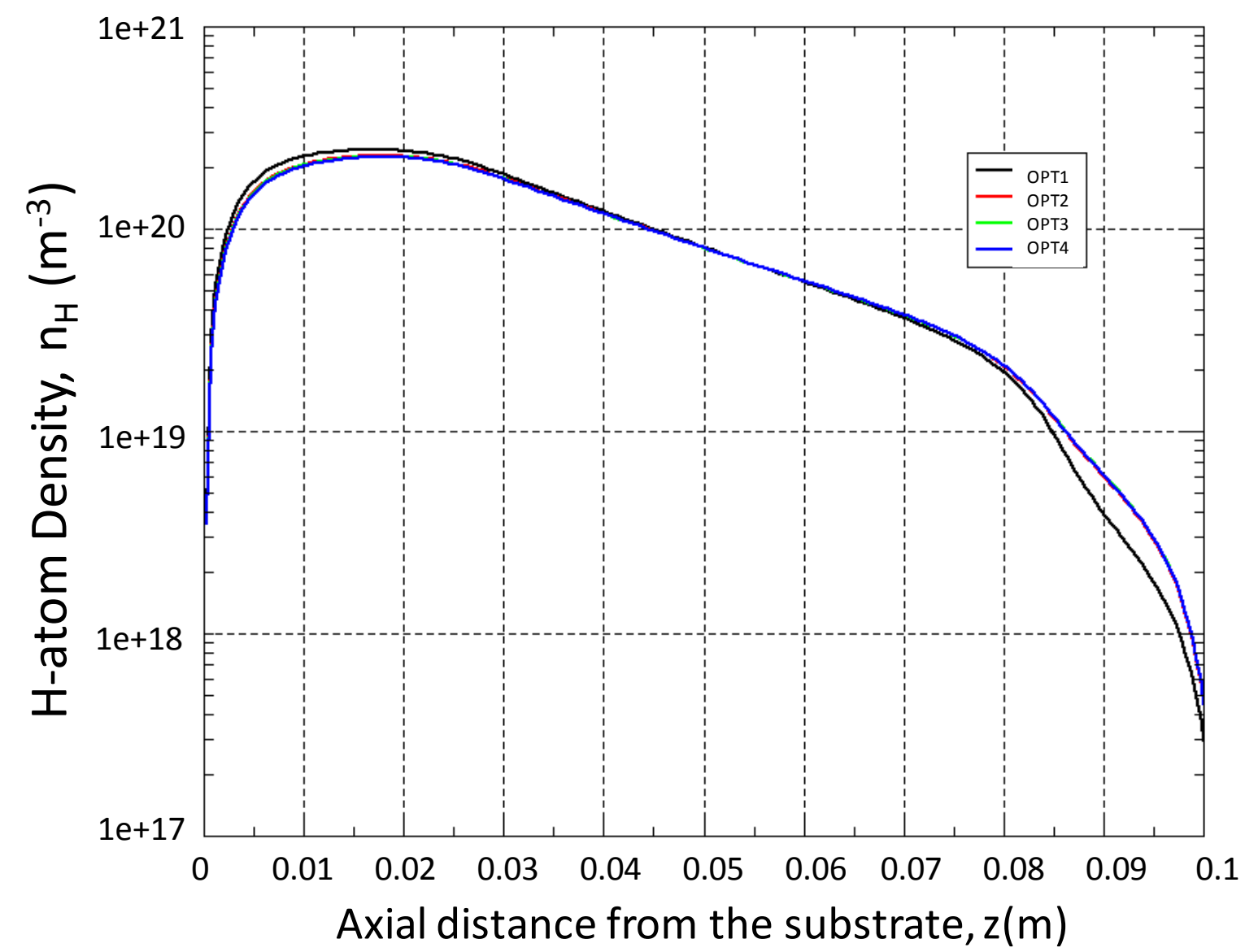

Figure 19. Calculated H-atom density profile from Table 3, OPT 1 to OPT 4 conditions.

Computational simulations were also run for all conditions considered in the parametric study outlined in Table 3. Figure 19 shows a plot of the calculated axial profiles of H-atoms. Indeed, atomic hydrogen not only plays an important role in the gas-phase chemistry but is also believed to be an essential element in the graphene growth process. As evident in Figure 19, little difference is observed among the profiles OPT2 to OPT4, whereas that of OPT1 shows a slightly increased molar concentration and a higher $\mathrm{H}$ atom gradient. This result is attributable to the similarity between the plasma power and the pressure of OPT 1 and OPT 4 because only the substrate temperatures were varied with OPT at $700{ }^{\circ} \mathrm{C}$ and the remaining temperatures were close to $850{ }^{\circ} \mathrm{C}$. This observation indicates that the surface temperature can influence the species gradients in the boundary layer, which is important for the growth of graphene. The MW-plasma coupling is weakly affected by the substrate temperature. This result is also in agreement with the actinometry measurements shown in Figure 10. Furthermore, graphene growth is temperature activated and can affect the species gradients in the boundary layer. This effect has not been modeled in the present self-consistent model and must be incorporated to improve 
the results of the 2D auto-coherent model and the predicted growth of graphene. Although these computational simulations do not predict the experimentally observed trends, they do provide order-of-magnitude estimates of the species concentrations and valuable insights into the complex, highly nonequilibrium behavior of the reactive microwave plasma used for graphene growth.

\section{Discussion}

Quantitative understanding of the gas-phase chemistry in PECVD $\mathrm{H}_{2} / \mathrm{CH}_{4}$ plasma is one important step toward elucidating graphene growth mechanism. The function of plasma is to create atomic hydrogen and hydrocarbon species $\mathrm{C}_{\mathrm{x}} \mathrm{H}_{\mathrm{y}}$, that diffuses to the catalyst surface and contribute to graphene growth. The role of $\mathrm{H}$ atoms in the plasma is the activation and cycling of hydrocarbon species. In addition $\mathrm{H}$-atoms improve the removal of the native metal oxide. It is expected that the growth mechanism of graphene depends on the carbon solubility in the metal catalyst exposed to the plasma. For high-carbon-solubility metals such as cobalt (Figure 20-a), bulk diffusion of all carbon precursors $\left(\mathrm{CH}_{4}, \mathrm{C}_{2} \mathrm{H}_{2}\right.$ and $\left.\mathrm{CH}_{3}\right)$ inside the cobalt lattice is possible at relatively high temperature $\left(700-900^{\circ} \mathrm{C}\right)$. It is difficult to estimate the relative diffusion rates of these species inside a polycristalline cobalt, but once the increasing dynamic concentration of carbon species reaches critical supersaturation level, the nucleation of graphene takes place and the net flux to the surface of all carbon species could be determinant. While cooling the substrate, the solubility of carbon in the cobalt decreases, and a thin film of carbon is thought to precipitate from the surface. Hence, the number of graphene layers formed depends on the thickness of the substrate and the cooling rate. In the opposite situation, when the solubility of carbon in the metal catalyst is low, such as for copper, the mechanism involves a radical opposite surface diffusive growth (Figure $20 \mathrm{~b}$-d). In this case, after the formation of stable nucleus on the top of the copper surface, hydrocarbon species $\mathrm{CH}_{\mathrm{x}}$ from the plasma with enough energy reach the graphene domain edge and attach to graphene lattice following a surface kinetics. Since the graphene exhibits fast growth in the [2ד10] direction and slow growth in the [10ī0] direction, the typical hexagons domain is formed as it growth. Atomic hydrogen $\mathrm{H}$ could form also dissociative carbon species. The equilibrium between diffusion, attachment to domain edge and detachment is controlled by $\mathrm{CH}_{\mathrm{x}}$ and $\mathrm{H}$ surface concentrations as well by the temperature. The best evidence of this assumption is the three regimes with typical known shapes of graphene domains observed experimentally for CVD graphene growth on copper at different temperatures [107]. (i) dendritic graphene under the control of diffusion-limited growth mechanism at low surface temperature $\left(\sim 1050^{\circ} \mathrm{C}\right)$ Figure 20 -b (ii) hexagons with sharp edges for attachment limited growth for intermediate surface temperature $\left(\sim 1100^{\circ} \mathrm{C}\right)$ Figure 20 -c and (iii) circular graphene domains for detachment-limited growth at high surface temperature $\left(\sim 1150^{\circ} \mathrm{C}\right)$ Figure 20 -d. 


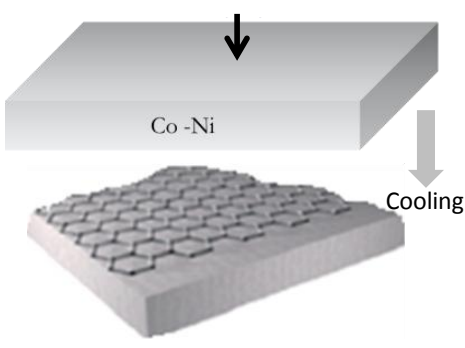

(a) Diffusion-segregation-reject growth

$\mathrm{CH}_{4}, \mathrm{C}_{2} \mathrm{H}_{2}, \mathrm{CH}_{3}$ etc.. dissolution

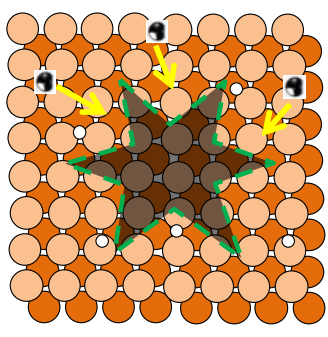

(b) Diffusion-limited growth

(3) $\mathrm{C}_{x} \mathrm{H}_{\mathrm{y}}$

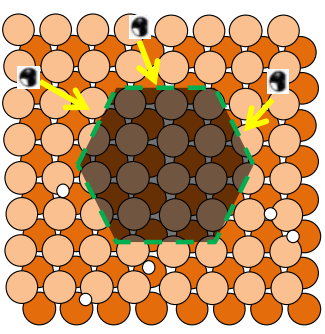

(c) Attachment-limited growth

Atomic hydrogen

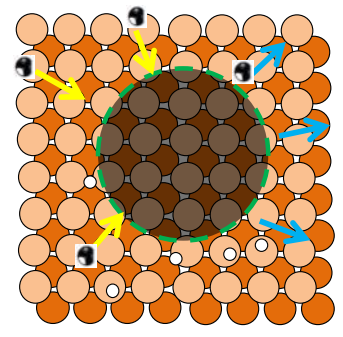

(d) Detachment-limited growth Copper

Attachment of $\mathrm{CxHy}$ on graphene lattice

$\rightarrow$ Detachment of $\mathrm{CxHy}$ from graphene lattice

Figure 20. Schematics of graphene growth on (a) low carbon solubility cobalt substrate and (b-c) high carbon solubility copper substrate at different substrate temperature.

\section{CONCLUSIONS}

A microwave PECVD reactor used for graphene synthesis was analyzed under specific graphene growth conditions with a power $\leq 580 \mathrm{~W}$ and a pressure $\leq 25$ mbar. In situ measurements were performed using OES for a microwave-plasma-activated hydrogen above cobalt and copper growth surfaces. The experimental results indicate that the rotational temperature varies with the plasma power, from $950 \mathrm{~K}$ (at $340 \mathrm{~W}$ ) to $1250 \mathrm{~K}$ (at 580 W). The pressure was simultaneously varied from 10 mbar to 25 mbar to maintain a constant plasma volume. Partial evaporation or plasma etching of the copper substrate was observed. Adding a few mole percent of methane did not affect the rotational temperature, as measured through the emission of the $\mathrm{H}_{2}$ Fulcher- $\alpha$ system. The relative densities of $\mathrm{H}(\mathrm{n}=1)$ atoms were also determined by actinometry under specific graphene conditions and showed a mole percent of 3 to $4.5 \%$. Best conditions to grow graphene from PECVD experiments using cobalt catalyst was found to be substrate temperature, $\mathrm{Ts}=870^{\circ} \mathrm{C}$, pressure $\mathrm{P}=13 \mathrm{mbar}$, methane and hydrogen flowrates $\Phi C H 4=1 \mathrm{sccm}, \Phi H 2=50 \mathrm{sccm}$ and microwave power Pmw=400 W.To further explore aspects of the plasma chemistry prevailing in the reactor and to consider chemical and energetic effects, two nonequilibrium computational models were developed to estimate the relative importance of individual phenomena and to simulate the plasma properties under specific graphene growth. The 0D model extends the classical chemistry formulation to nonequilibrium plasma reactors that include three temperatures $-\mathrm{T}, \mathrm{T}_{\mathrm{e}}$ and $\mathrm{T}_{\mathrm{v}}$ as well as 119 species involved in 336 gas-phase reactions. Surface recombination and detailed power deposition with inelastic and elastic collision losses are considered by assuming an electron energy distribution function (EEDF). The problem reduces to solving a set of stiff DAE to simultaneously determine steady-state mole fractions and 
temperatures. Sensitivity analyses provide the quantitative dependence of the solution model on parameter perturbations, yielding guidelines for optimizing the $\mathrm{H}$-atom and carbon precursors production in the reactor. A typical CPU time for solving the overall problem is $5 \mathrm{~s}$ on a Core i7 machine with $16 \mathrm{~GB}$ of RAM. Another advantage of the OD model is the consideration of vibration chemistry represented by the vibrational temperature and sophisticated plasma chemistry with PAH. Nevertheless, the OD model does not describe spatial multidimensional aspects of the problem and admit a boundary layer thickness as a parameter. For these reasons, a $2 \mathrm{D}$ auto-coherent model is proposed to solve the essential physics with gas and electron energy equations along with a reduced chemistry scheme to reduce the computational load. Despite the differences in the approaches, inherent to each model assumption, their validity under the prevailing experimental conditions is demonstrated. The $0 \mathrm{D}$ and $2 \mathrm{D}$ models show a relatively low gas temperature of $1600 \mathrm{~K}$ that is higher than the measured rotational temperature, suggesting that the $\mathrm{H}_{2}$ rotational temperature underestimates the gas temperature. Numerical results indicate that the addition of a few mole percent of methane to the hydrogen microwave plasma affects the plasma chemistry and the energy distribution. The 2D model indicates that little difference exists between the different optimum conditions on the MW-plasma coupling. This small difference is primarily explained by the temperature-controlled nature of the graphene growth.

The graphene growth process is a multiphysics problem that requires a detailed chemistry scheme as well as transport and energy relaxation pathways to capture all of the important precursors. Constructing a model that can capture all these effects is challenging. To a certain extent, the 0D model captures the detailed chemistry with an inherent limitation consisting of the absence of diffusion from the cold regions of the cavity, which is found to be important from $2 \mathrm{D}$ simulations. However, the reduced chemistry model used in the $2 \mathrm{D}$ simulations is insufficient for drawing conclusions about the species concentrations and graphene growth precursors. Nevertheless, the qualitative comparisons between the experiments and the models are fairly satisfactory and the consideration of surface chemistry coupled with these models is currently under development.

\section{ACKNOWLEDGEMENTS}

We thank Dr Carl D. Scott from Johnson Space Center, Houston TX for his valuable and constructive suggestions during models development. «ANR (Agence Nationale de la Recherche) and CGI (Commissariat à l'Investissement d'Avenir) are gratefully acknowledged for their financial support of this work through Labex 
SEAM (Science and Engineering for Advanced Materials and devices) ANR 11 LABX 086, ANR 11 IDEX 05 02 ». L'Agence Universitaire de la Francophonie (AUF) and the Fund "Scientific Research", Bulgaria are gratefully acknowledged for their financial support of this work through bilateral project TherMoVapCar. 


\section{REFERENCES}

[1] K. S. Novoselov, A. K. Geim, S. V. Morozov, D. Jiang, Y. Zhang, S. V. Dubonos, I. V. Grigorieva, and A. A. Firsov 2004 Science 306666

[2] K. S. Kim, Y. Zhao, H. Jang, S. Y. Lee, J. M. Kim, K. S. Kim, J.-H. Ahn, P. Kim, J.-Y. Choi, and B. H. Hong 2009 Nature 457 706-710

[3] J. K. Wassei and R. B. Kaner 2010 Mater. Today 13 52-59

[4] E. Singh and H. Nalwa 2015 J. Nanosci. Nanotechnol. 15 6237-6278

[5] F. Bonaccorso, Z. Sun, T. Hasan, and A. C. Ferrari 2010 Nat. Photonics 4 611-622

[6] M. Bernardi, M. Palummo, and J. C. Grossman 2013 Nano Lett. 13 3664-3670

[7] S. Hu et al. 2014 Nature 516 227-230

[8] F. Kafiah, Z. Khan, A. Ibrahim, M. Atieh, and T. Laoui 2017 Materials 1086

[9] R. R. Nair, H. A. Wu, P. N. Jayaram, I. V. Grigorieva, and A. K. Geim 2012 Science 335 442-444

[10] D. Cohen-Tanugi, L.-C. Lin, and J. C. Grossman 2016 Nano Lett. 16 1027-1033

[11] X. Li et al. 2009 Science 3241312

[12] A. Reina, X. Jia, J. Ho, D. Nezich, H. Son, V. Bulovic, M. S. Dresselhaus, and J. Kong 2009 Nano Lett. 9 $30-35$

[13] X. Li, L. Colombo, and R. S. Ruoff 2016 Adv. Mater. 28 6247-6252

[14] S. Bae et al. 2010 Nat. Nanotechnol. 5 574-578

[15] T. Hesjedal 2011 Appl. Phys. Lett. 98133106

[16] T. Yamada, M. Ishihara, J. Kim, M. Hasegawa, and S. Iijima 2012 Carbon 50 2615-2619

[17] I. Vlassiouk, P. Fulvio, H. Meyer, N. Lavrik, S. Dai, P. Datskos, and S. Smirnov 2013 Carbon 54 58-67

[18] T. Kobayashi et al. 2013 Appl. Phys. Lett. 102023112

[19] E. S. Polsen, D. Q. McNerny, B. Viswanath, S. W. Pattinson, and A. John Hart 2015 Sci Rep. 510257

[20] O. Rader, A. Varykhalov, J. Sanchez-Barriga, D. Marchenko, A. Rybkin, and A. M. Shikin 2009 Phys. Rev. Lett. 102057602

[21] D. Eom, D. Prezzi, K. T. Rim, H. Zhou, M. Lefenfeld, S. Xiao, C. Nuckolls, M. S. Hybertsen, T. F. Heinz, and G. W. Flynn 2009 Nano Lett. 9 2844-2848

[22] H. I. Rasool, E. B. Song, M. J. Allen, J. K. Wassei, R. B. Kaner, K. L. Wang, B. H. Weiller, and J. K. Gimzewski 2011Nano Lett. 11 251-256

[23] Z. Sun, Z. Yan, J. Yao, E. Beitler, Y. Zhu, and J. M. Tour 2010 Nature 468 549-552

[24] L. Gao, J. R. Guest, and N. P. Guisinger 2010 Nano Lett. 10 3512-3516

[25] M. Xu, D. Fujita, K. Sagisaka, E. Watanabe, and N. Hanagata 2011 ACS Nano 5 1522-1528

[26] Q. Yu, J. Lian, S. Siriponglert, H. Li, Y. P. Chen, and S.-S. Pei 2008 Appl. Phys. Lett. 93113103

[27] A. Cabrero-Vilatela, R. S. Weatherup, P. Braeuninger-Weimer, S. Caneva, and S. Hofmann 2016

Nanoscale 8 2149-2158

[28] K. Yamamoto, M. Fukushima, T. Osaka, and C. Oshima 1992 Phys. Rev. B 45 11358-11361

[29] J. Lahiri, T. Miller, L. Adamska, I. I. Oleynik, and M. Batzill 2011 Nano Lett. 11 518-522

[30] S.-Y. Kwon, C. V. Ciobanu, V. Petrova, V. B. Shenoy, J. Bareno, V. Gambin, I. Petroy, and S. Kodambaka 2009 Nano Lett. 9 3985-3990

[31] T. Fujita, W. Kobayashi, and C. Oshima 2005 Surf. Interface Anal. 37120 
[32] P. Sutter, J. T. Sadowski, and E. Sutter 2009 Phys. Rev. B 80245411

[33] X. Feng, J. Wu, A. T. Bell, and M. Salmeron 2015 J. Phys. Chem. C 119 7124-7129

[34] P. W. Sutter, J.-I. Flege, and E. A. Sutter 2008 Nat. Mater. 7 406-411

[35] E. Loginova, N. C. Bartelt, P. J. Feibelman, and K. F. McCarty 2008 New J. Phys. 10093026

[36] E. Loginova, N. C. Bartelt, P. J. Feibelman, and K. F. McCarty 2009 New J. Phys. 11063046

[37] J. Coraux, A. T. N'Diaye, M. Engler, C. Busse, D. Wall, N. Buckanie, F.-J. Meyer zu Heringdorf, R. van

Gaste, B. Poelsema, and T. Michely 2009 New J. Phys. 11023006

[38] E Loginova, S. Nie, K. Thurmer, N. C. Bartelt, and K. F. McCarty 2009 Phys. Rev. B 80085430

[39] J. Coraux, A. T. N'Diaye, C. Busse, and T. Michely 2008 Nano. Lett. 8 565-570

[40] P. Lacovig, M. Pozzo, D. Alfe, P. Vilmercati, A. Baraldi, and S. Lizzit 2009 Phys. Rev. Lett. 103166101

[41] E. N. Voloshina, Y. S. Dedkov, S. Torbrugge, A. Thissen, and M. Fonin 2012 Appl. Phys. Lett. 100241606

[42] N. A. Vinogradov et al. 2012 Phys. Rev. Lett. 109026101

[43] S. Nie, N. C. Bartelt, J. M. Wofford, O. D. Dubon, K. F. McCarty, and K. Thurmer 2012 Phys. Rev. B 85 205406

[44] X. Liu, L. Fu, N. Liu, T. Gao, Y. Zhang, L. Liao, and Z. Liu 2011 J. Phys. Chem. C 115 11976-11982

[45] T. Wu et al. 2016 Nat. Mater. 15 43-47

[46] Z. Gao et al. 2018 ACS Nano 12 2275-2282

[47] I. V. Vlassiouk et al. 2018 Nat. Mater. 17 318- 332

[48] P. T. Trung, J. Campos-Delgado, F. Joucken, J.-F. Colomer, B. Hackens, J.-P. Raskin, C. N. Santos, and S. Robert 2014 J. Appl. Phys. 115223704

[49] I. Pasternak, M. Wesolowski, I. Jozwik, M. Lukosius, G. Lupina, P. Dabrowski, J. M. Baranowski, and W. Strupinski 2016 Sci. Rep. 621773

[50] M. Lukosius et al. 2016 ACS Appl. Mater. Interfaces 8 33786-33793

[51] J. Dabrowski et al. 2016 Sci. Rep. 631639

[52] In ASM Handbook: Alloy Phase Diagrams, Volume 3 (ASM International, USA, 2002)

[53] C. Oshima and A. Nagashima 1997 J. Phys. Condens. Matter 91

[54] X. Li, W. Cai, L. Colombo, and R. S. Ruoff 2009 Nano Lett. $94268-4272$

[55] T. Liang, Y. Kong, H. Chen, and M. Xu 2016 Chin. J. Chem. 34 32-40

[56] H. Ji et al. 2011 ACS Nano 5 7656-7661

[57] G. Ruan, Z. Sun, Z. Peng, and J. M. Tour 2011 ACS Nano 5 7601-7607

[58] Z. Li, P. Wu, C. Wang, X. Fan, W. Zhang, X. Zhai, C. Zeng, Z. Li, J. Yang, and J. Hou 2011 ACS Nano 5 $3385-3390$

[59] J. K. Wassei, M. Mecklenburg, J. A. Torres, J. D. Fowler, B. C. Regan, R. B. Kaner, and B. H. Weiller 2012 Small 8 1415-1422

[60] B. Luo, E. Gao, D. Geng, H. Wang, Z. Xu, and G. Yu 2017 Chem. Mater. 29 1022-1027

[61] M. R. Habib, T. Liang, X. Yu, X. Pi, Y. Liu, and M. Xu 2018 Rep. Prog. Phys. 81036501

[62] R. Piner et al. 2013 ACS Nano 7 7495-7499

[63] M. Seifert, S. Drieschner, B. M. Blaschke, L. H. Hess, and J. A. Garrido 2014 Diam. Relat. Mater. 47 4652

[64] C. Wu, F. Li, W. Chen, C. P. Veeramalai, P. C. Ooi, and T. Guo 2015 Sci. Rep. 59034 
[65] J. Wang, M. Zhu, R. A. Outlaw, X. Zhao, D. M. Manos, and B. C. Holloway 2004 Carbon 422867

[66] A. Malesevic, R. Vitchev, K. Schouteden, A. Volodin, L. Zhang, G. V. Tendeloo, A. Vanhulsel, and C. V. Haesendonck 2008 Nanotechnology 19305604

[67] G. D. Yuan et al. 2009 Chem. Phys. Lett. 467 361-364

[68] M. Kim, N. S. Safron, E. Han, M. S. Arnold, and P. Gopalan 2010 Nano Lett. 101125

[69] G. Nandamuri, S. Roumimov, and R. Solanki 2010 Appl. Phys. Lett. 96154101

[70] G. Kalita, K. Wakita, and M. Umeno 2012 RSC Adv. 2 2815-2820

[71] T. Yamada, M. Ishihara, and M. Hasegawa 2013 Thin Solid Films 532 89-93

[72] J. Kim, M. Ishihara, Y. Koga, K. Tsugawa, M. Haseqawa, and S. Iijima 2011 Appl. Phys. Lett. 98091502

[73] Z. Bo, Y. Yang, J. Chen, K. Yu, J. Yan, and K. Cen 2013 Nanoscale 55180

[74] J. Sun, Y. Chen, M. Kr. Priydarshi, Z. Chen, A. Bachmatiuk, Z. Zou, Z. Chen, X. Song, Y. Gao, M. H. Rummeli, and Y. Zhang 2015 Nano Lett. 155846

[75] D. A. Boyd et al. 2015 Nat. Commun. 66620

[76] A. Mehedi, B. Baudrillart, D. Alloyeau, O. Mouhoub, C. Ricolleau, V. D. Pham, C. Chacon, A. Gicquel, J. Lagoute, and S. Farhat 2016 J. Appl. Phys. 120065304

[77] G. Shivkumar, S. S. Tholeti, M. A. Alrefae, T. S. Fisher, and A. A. Alexeenko 2016 J. Appl. Phys. 119 113301

[78] H. Kim, E. Saiz, M. Chhowalla, and C. Mattevi 2013 New J. Phys. 15053012

[79] P. Trinsoutrot, C. Rabot, H. Vergnes, A. Delamoreanu, A. Zenasni, and B. Caussat 2014 Chem. Vap. Deposition 20 51-58

[80] D. Tsyganov, N. Bundaleska, E. Tatarova, A. Dias, J. Henriques, A. Rego, A. Ferraria, M. V. Abrashev, F. M. Dias, C. C. Luhrs, and J. Phillips 2016 Plasma Sources Sci. Technol. 25015013

[81] Bundaleska N., Tsyganov D., Dias A., Felizardo E., Henriques J., Dias F. M., Abrashev M., Kissovski J., Tatarova E. // Phys. Chem. Chem. Phys. 59 (2018) 4; doi: 10.1039/C8CP01896K

[82] A. A. Puretzky, I. A. Merkulov, C. M. Rouleau, G. Eres, and D. B. Geohegan 2014 Carbon 79 256-264

[83] K. Al-Shurman, H. Naseem, Proceedings of the 2014 COMSOL Conference in Boston (2014)

[84] K. Al-Shurman, Ph.D. Thesis, University Of Arkansas, Fayetteville (2015)

[85] A. Gicquel, K. Hassouni, S. Farhat, Y. Breton, C. D. Scott, M. Lefebvre, and M. Pealat 1994 Diam. Relat. Mater. 3 581-586

[86] T. Lang, J. Stiegler, Y. von Kaenel, and E. Blank 1996 Diam. Relat. Mater. 5 1171-1184

[87] A. Gicquel, K. Hassouni, Y. Breton, M. Chenevier, and J. C. Cubertafon 1996 Diam. Relat. Mater. 5 366372

[88] A. Gicquel, M. Chenevier, Y. Breton, M. Petiau, J. P. Booth, and K. Hassouni 1996 J. Phys. III France 6 $1167-1180$

[89] A. Gicquel, M. Chenevier, K. Hassouni, A. Tserepi, and M. Dubus 1998 J. Appl. Phys. 837504

[90] K. Hassouni, T. A. Grotjohn, and A. Gicquel 1999 J. Appl. Phys. 86134

[91] J. Ma, M. N. R. Ashfold, and Y. A. Mankelevich 2009 J. Appl. Phys. 105043302

[92] K. Hassouni, F. Silva, and A. Gicquel 2010 J. Phys. D: Appl. Phys. 43153001

[93] E. J. D. Mahoney, B. S. Truscott, M. N. R. Ashfold, and Y. A. Mankelevich 2017 J. Phys. Chem. A 121 $2760-2772$ 
[94] R. K. Garg, T. N. Anderson, R. P. Lucht, T. S. Fisher, and J. P. Gore 2008 J. Phys. D: Appl. Phys. 41 095206

[95] J. Ropcke, M. Kaning, and B. P. Lavrov 1998 J. Phys. IV France 8 207-216

[96] A.S.C. Nave, B. Baudrillart, S. Hamann, F. Bénédic, G. Lombardi, A. Gicquel, J.H. van Helden, J. Röpcke 2016 Plasma Sources Sci. Technol. 2565002

[97] L. Tomasini, A. Rousseau, G. Gousset, and P. Leprince 1996 J. Phys. D: Appl. Phys. 291006

[98] E. J. Tonnis and D. B. Graves 2002 J. Vac. Sci. Technol. A 20 1787-1795

[99] G. H. Dieke, The hydrogen molecule wavelength tables of Gerhard Heinrich Dieke, edited by H. Crosswhite (John Wiley \& Sons Inc, USA, 1972)

[100] Z. Qing, D. Otorbaev, G. Brussaard, M. Van de Sanden, and D. Schram 1996 J. Appl. Phys. 80 1312-1324

[101] J. W. Coburn and M. Chen 1980 J. Appl. Phys. 513134

[102] C. D. Scott, S. Farhat, A. Gicquel, K. Hassouni, and M. Lefebvre 1996 J. Thermophys. Heat Tr. 10 426435

[103] S. Prasanna, C. Rond, A. Michau, K .Hassouni, and A. Gicquel 2016 Plasma Sources Sci.Technol. 25 045017

[104] S. Prasanna, A. Michau, C. Rond, K. Hassouni, and A. Gicquel 2017 Plasma Sources Sci. Technol. 26 097001

[105] M. Hanif, M. Salik, and M. A. Baig 2011 Opt. Laser Eng. 49 1456-1461

[106] S. Sinha, R. K. Rahman, and A. Raj 2017 Phys. Chem. Chem. Phys. 29 19262-19278

[107] C. Wu et al. " Electromagnetic induction heating for single crystal graphene growth: morphology control by rapid heating and quenching", Scientific Reports volume 5, Article number: 9034 (2015) 


\section{LIST OF FIGURES}

Figure 1. PECVD Bell jar reactor used for graphene growth: (a) scheme and (b) picture of the plasma on the substrate holder during graphene growth.

Figure 2. Photography of the PECVD reactor with the optical emission spectroscopy (OES) setup.

Figure 3. Photography (left) and top view scheme (right) of the optical emission spectroscopy (OES) setup.

Figure 4. Modeling approaches in CVD.

Figure 5. Example of measured $\mathrm{H}_{2}$ Fulcher- $\alpha$ Q-branch spectrum with indication to the selected rotational lines at microwave power of $390 \mathrm{~W}$ and total pressure of 13 mbar. The inset shows the corresponding Boltzmann plot.

Figure 6. $\mathrm{H}_{2}$ rotational temperature measured by OES as a function of input microwave power.

Figure 7. $\mathrm{H}_{2}$ rotational temperature measured by OES at the optimal graphene growth conditions of Table 3.

Figure 8. Copper lines observed from emission spectrum in pure hydrogen when copper catalyst is used. Microwave power $=390 \mathrm{~W}$, pressure $=13$ mbar and substrate temperature $=980{ }^{\circ} \mathrm{C}$. The stars refers to the copper lines as obtained from emission spectrum of neutral and ionized copper plasma in Ref.112.

Figure 9. Atomic hydrogen mole fraction determined from actinometry as a function of input microwave power.

Figure 10. Atomic hydrogen mole fraction as determined from actinometry in the optimal graphene growth conditions of Table 3 .

Figure 11. Time evolution of small $C_{1}-C_{2}$ carbon species mole fractions calculated from Table 3 , OPT 1 conditions. Global reaction transforming input methane to acetylene. Ts $=700^{\circ} \mathrm{C}, \mathrm{P}=13 \mathrm{mbar}, \Phi_{\mathrm{CH} 4}=1 \mathrm{sccm}$, $\Phi_{\mathrm{H} 2}=50 \mathrm{sccm}$ and $\mathrm{P}_{\mathrm{mw}}=400 \mathrm{~W}$.

Figure 12. Major species calculated from Table 3, OPT 1 conditions. Ts $=700^{\circ} \mathrm{C}, \mathrm{P}=13 \mathrm{mbar}, \Phi_{\mathrm{CH} 4}=1 \mathrm{sccm}$, $\Phi_{\mathrm{H} 2}=50 \mathrm{sccm}$ and $\mathrm{P}_{\mathrm{mw}}=400 \mathrm{~W}$.

Figure 13. Time evolution of $\mathrm{H}$ atoms, electrons and positive and negative ions mole fractions calculated from Table 3, OPT 1 conditions. The species are classified in their order of abundance in the legend. Ts $=700^{\circ} \mathrm{C}, \mathrm{P}=13$ mbar, $\Phi_{\mathrm{CH} 4}=1 \mathrm{sccm}, \Phi_{\mathrm{H} 2}=50 \mathrm{sccm}$ and $\mathrm{P}_{\mathrm{mw}}=400 \mathrm{~W}$.

Figure 14. Time evolution of polycyclic aromatic hydrocarbons (PAHs) carbon species calculated from Table 3 , OPT 1 conditions. $\mathrm{Ts}=700^{\circ} \mathrm{C}, \mathrm{P}=13 \mathrm{mbar}, \Phi_{\mathrm{CH} 4}=1 \mathrm{sccm}, \Phi_{\mathrm{H} 2}=50 \mathrm{sccm}$ and $\mathrm{P}_{\mathrm{mw}}=400 \mathrm{~W}$.

Figure 15. Electron, gas and vibration temperatures, absorbed power and electron and vibration energy exchange calculated for OPT 1 conditions. Ts $=700^{\circ} \mathrm{C}, \mathrm{P}=13 \mathrm{mbar}, \Phi_{\mathrm{CH} 4}=1 \mathrm{sccm}, \Phi_{\mathrm{H} 2}=50 \mathrm{sccm}$ and $\mathrm{P}_{\mathrm{mw}}=400 \mathrm{~W}$. 
Figure 16. Contours of (a) gas temperature $\mathrm{T}$ and (b) electron temperature $\mathrm{T}_{\mathrm{e}}$ calculated from Table 3 , OPT 3 conditions. $\mathrm{z}$ and $\mathrm{r}$ are axial and radial position in meters, respectively $\mathrm{Ts}=870^{\circ} \mathrm{C}, \mathrm{P}=13 \mathrm{mbar}, \Phi_{\mathrm{CH} 4}=1 \mathrm{sccm}, \Phi_{\mathrm{H} 2}=50 \mathrm{sccm}$ and $\mathrm{P}_{\mathrm{mw}}=400 \mathrm{~W}$.

Figure 17. (a) Electron density and (b) absorbed power density contours. Calculated from Table 3, OPT 3 conditions. $\mathrm{z}$ and $\mathrm{r}$ are axial and radial position in meters, respectively. $\mathrm{Ts}=870^{\circ} \mathrm{C}, \mathrm{P}=13 \mathrm{mbar}, \Phi_{\mathrm{CH} 4}=1 \mathrm{sccm}$, $\Phi_{\mathrm{H} 2}=50 \mathrm{sccm}$ and $\mathrm{P}_{\mathrm{mw}}=400 \mathrm{~W}$.

Figure 18. Specie mole fraction contours for $\mathrm{H}, \mathrm{CH}_{3}, \mathrm{CH}_{4}, \mathrm{C}$ (Top from left to right) and $\mathrm{C}_{2} \mathrm{H}_{2}, \mathrm{C}_{2}, \mathrm{C}_{2} \mathrm{H}_{3}{ }^{+}$and $\mathrm{C}_{2} \mathrm{H}_{5}{ }^{+}$(Bottom from left to right) calculated from Table 3, OPT 3 conditions. $\mathrm{z}$ and $\mathrm{r}$ are axial and radial position in meters, respectively. $\mathrm{Ts}=870^{\circ} \mathrm{C}, \mathrm{P}=13 \mathrm{mbar}, \Phi_{\mathrm{CH} 4}=1 \mathrm{sccm}, \Phi_{\mathrm{H} 2}=50 \mathrm{sccm}$ and $\mathrm{P}_{\mathrm{mw}}=400 \mathrm{~W}$.

Figure 19. Calculated H-atom density profile from Table 3, OPT 1 to OPT 4 conditions.

\section{LIST OF TABLES}

Table 1. Transition wavelengths, upper and lower level assignments of the measured species and energies for the tracers.

Table 2. Operating conditions for hydrogen plasma

Table 3. Set of parameters obtained for optimal Graphene growth as determined in Ref. 76. 